\title{
Decentralization Of The Firm: Theory And Evidence
}

\author{
Andrew A. Christie* \\ Marc P. Joye ${ }^{+}$ \\ Ross L. Watts* \\ William E. Simon Graduate School \\ of Business Administration \\ University of Rochester \\ Rochester, NY 14627 \\ Phone: (716) 275-4714 \\ Fax: (716) 442-6323 \\ E-Mail: Christie @SSBIBM.SSB.ROCHESTER.EDU \\ December 1993 \\ First Version: November 1989
}

\begin{abstract}
Jensen and Meckling (1992) hypothesize that the firm's decentralization decision is determined by a tradeoff of knowledge transfer costs and control (agency) costs. To maximize value, either knowledge must be transferred to those with the right to make decisions or decision rights must be transferred to those who have the knowledge. We identify characteristics of firms' investment opportunity sets that affect knowledge transfer and control costs and generate testable predictions about the relations between these characteristics and firms' decentralization decisions. The evidence we present is generally consistent with our predictions and is robust to different ways of measuring variables.
\end{abstract}

\footnotetext{
* University of Rochester. ${ }^{+}$Union Bank of Switzerland. Financial support was provided by the John M. $\mathrm{O}^{1:}$ " Foundation and the Bradley Research Center of the University of Rochester. We thank Mike 马a : ay, Ron Dye, Mike Jensen, Bnice Johnsen, Ken Lehn, Tom Lys, Bob Magee, Pat O'Brien, Jerry Zimmerman, an anonymous referee, and participants in workshops at the University of Arizona, Cornell University, Drexel University, Harvard University, the University of Michigan, Northwestern University, the University of Pittsburg, the University of Utah Winter Finance Conference and the Office of Economic Analysis at the Securities and Exchange Commission for helpful comments. We also thank Jim Maloney for excellent research assistance.
} 


\section{Decentralization and the Investment Opportunity Set}

\section{Introduction}

This paper provides evidence on the empirical relations between the decentralization of decision rights within the firm and observable characteristics of the firm's investment opportunity set. Decentralization within the firm is complex, involving delegation of some decision rights and not others from one managerial level to another, and the splitting of decision rights for a particular proposal among different individuals (Meckling and Jensen, 1986). This complexity makes modeling decentralization difficult and the extant formal and informal models are necessarily relatively simple.' Simplicity is a virtue if the model captures the essence of decentralization and is descriptive. Knowledge of systematic empirical associations between decentralization and firm attributes contributes to selecting anong existing models and building more descriptive models.

We use existing models to select variables representing decentralization of decision rights and firm attributes expected to be associated with decision rights. The level of delegation investigated is from the CEO to the next management level below the CEO. ${ }^{2}$ In this version of the paper, the organization of that level into profit and cost centers is used to represent decentralization. Future versions will also use delegation of the investment decision and the ability to substitute across budget line items to measure decentralization both individually and in combination. The three decentralization variables are obtained from firms' responses to a questionnaire.

The firm characteristics used in empirical work are the type of knowledge in the firm's industry, interdependence of the firm's investments, regulation and firm size. Measures of these firm attribute variables are initially obtained from questionnaire responses and public data sources. We find that the use of profit and cost centers is robustly related to characteristics of the firm's investment opportunity set. Larger firms with more specialized knowledge, less dependent investments and no regulation are more likely to decentralize decision rights by using profit centers. That result is essentially invariant to the alternative specifications of the firm attribute variables that are employed. One specification uses questionnaire data only for the dependent variable and so can be used to predict decentralization for firms outside the sample.

\footnotetext{
${ }^{1}$ For examples of both formal and informal decentralization models see: Chandler (1962 and 1977); Williamson (1975); Simon (1976); Vancil (1978); Vaysman (1991); Melanud. Mookerjee and Rt ielstein (1992): Jensen and Meckling (1992): Milgrom and Roberts (1992); and Radner (1992)

${ }^{2}$ The term CEO (or CEO's office) refers to all components of the executive office. including the board of directors, chairman, president and any executive vice-presidents.
} 
To gain further insight into the empirical model's descriptive ability, the specification that uses only non-questionnaire independent variables is employed to predict the extent of decentralization in a sample corporation whose decentralization has also been assessed in the business media in the period 1990 to 1993 (Caterpillar). In future versions we will search for more in-and out-of sample corporations whose decentralization is assessed in the media to use to assess the model.

The next section (section 2) discusses the measures of decentralization. Section 3 develops the knowledge type characteristic of the firm's investment opportunity set, its expected relations to decentralization and empirical measures. The interdependence of investments, regulation, and firms size characteristics are discussed in section 4 and measures developed. Descriptive statistics are provided in section 5 and section 6 presents the empirical relations between the decentralization measure and investment characteristics. Section 7 presents the Caterpillar case. A summary and conclusion appear in the final section.

\section{Decentralization}

As noted above, the allocation of decision rights within the firm is complex. Some rights are kept by the CEO's executive office and others are delegated to the next level. Also, single decisions can be broken into different parts with the executive office handling some parts and the next level others. For example, investment decisions are often split into initiation, notification, ratification, implementation and monitoring tasks (see Meckling and Jensen, 1986). The lower level is given the right to initiate an investment project, but the executive office keeps the right to ratify the investment decision. The particular combination

of decentralized and centralized decision rights or parts of decision rights chosen depends on the costs and benefits of the different combinations.

Because some decision rights are centralized and others decentralized and decision rights are broken up, it is difficult to assess the overall degree of decentralization from the CEO to the next management level ("second level"). In this version of the paper, we use an instrumental variable for the general degree of decentralization, namely the relative use of profit and cost centers at the second level. According to Williamson (1975), Vancil (1978) and Meckling and Jensen (1986) profit-center managers typically have a broader set of decision rights than cost-center managers; profit centers are associated with more decentralization. In future versions of the paper, we will investigate the second level management's rights to initiate investment decisions and to substitute across budget line items.

The decentralization measures are obtained from a questionnaire (see appendix $\mathrm{A}$ ). The questionnaire asks the firm management to identify the second level and tell us whether the second 
level units are profit centers, cost centers or a mixture of the two. To avoid firms using different interpretations of the second level, we define in the questionnaire what we mean by the second level. The focus is on line units and so excludes functions such as finance and treasury.

\section{Knowledge Type Characteristics and Decentralization}

The literature on decentralization (Chandler, 1962 and 1977; Jensen and Meckling, 1992; Vancil, 1978; and Williamson, 1975) identifies several investment opportunity set characteristics that are likely to be associated with decentralization of the firm. Those characteristics are the type of knowledge involved in the firm's investments, the dependence among the firm's investments, the size of the firm's investments and whether or not the investments are regulated. The knowledge type, dependence and regulation characteristics are predetermined for the purposes of our analysis. The size characteristic is endogenous, but in the absence of a model explaining size we are forced to treat it as predetermined.

The characteristics are not independent. For example, whether or not an industry is regulated is related to the type of the knowledge generated within the industry. But, as we shall see, once an industry is regulated, regulation, per se, provides an incentive to centralize. Further, some characteristics are related to both the costs and benefits of decentralization so that the crosssectional empirical relation we estimate is a reduced form and it is difficult to interpret the characteristics' coefficients. Still, the existence of a cross-sectional relation between decentralization and the characteristics identified by theory provides some reassurance about the theory's relevance. In this section we explain why knowledge type attributes are expected to be related to decentralization and how we measure it.

\subsection{Knowledge type}

Organizations are more likely to survive if those with the responsibility for decisions also have the knowledge valuable to those decisions (Hayek, 1945; Harris, Kriebel and Raviv, 1982; and Jensen and Meckling, 1992). Collocation of decision rights with knowledge can be achieved by transferring the knowledge to the person who has the decision rights or by transferring the decision rights to the person with the knowledge. While the CEO has knowledge that lower levels do not, much of the literature assumes that knowledge is generated at the lower level. We also adopt that assumption so that transfer of knowledge is centralization and transfer of decision rights is decentralization. Both centralization and decentralization involve costs as well as benefits. Which (or how much of each) is optimal depends on the relative costs of transferring knowledge and transferring decision rights.

In part, knowledge transfer costs arise because decision-makers have limited mental and sensory faculties (see March and Simon , 1958, or Arrow, 1974). Effective use of knowledge in 
decisions requires a decision maker to understand the knowledge received. As Jensen and Meckling (1992, p. 4) put it, "Transfer ... means effective transfer not merely communication." Part of knowledge transfer costs is the residual loss that occurs because the decision-maker does not understand the knowledge well enough to act on it in a timely manner. Transfer costs also include out of pocket costs of transmitting the knowledge to the person with the decision rights and residual losses that arise from delays in this transmission process. Decentralization reduces knowledge transfer costs. ${ }^{3}$

The costs of transferring decision rights from the CEO to a lower level are control costs. In non-owner-managed firms, the labor, corporate control, capital and product markets provide the CEO with an incentive to act in the owners' interests. However, there is still some control cost in the form of residual loss in value because the CEO's incentives are not perfectly aligned with the owners' interests. Transferring decision rights from the CEO to lower-level managers increases control costs. Having lower-level managers make decisions in the owners' (or even the CEO's) interests requires costly systems for measuring and evaluating the lower-level manager's performance and rewarding or punishing their performance. Residual loss increases also if those systems do not perfectly align the lower-level manager's interests with those of the owners'. Decentralization increases control costs.

Organization of the firm depends on the relative magnitudes of knowledge transfer and control costs. Decision rights tend to remain in the CEO's office when the cost of transferring knowledge to the CEO is low, or when control costs are large relative to knowledge transfer costs. Decision rights tend to be delegated to lower levels of the firm when the firm primarily produces knowledge that is costly to transfer to the CEO or when control costs are relatively low.

\footnotetext{
${ }^{3}$ Papers by Melumad, Mooklierjee and Reiclelstein (1992) (MMR) and Vaysınan (1991) examine delegated decision making when communication between the CEO and other parts of the organization is re ${ }^{-r}$ icted. MMR examine demand for responsibility (profit and cost) centers, and Vaysman examines de. and for cost-based transfer prices when communication is limited. These papers refer to the benefit from delegating decision rights as the flexibility gain. In our terminology flexibility gain is a reduction in knowledge transfer costs.
} 
We adopt Demsetz' (1988) term "specialized" to refer to knowledge that is costly to transfer and "non-specialized" to refer to knowledge that can be transferred at low cost. ${ }^{4}$ We argue below that flows of knowledge (information) are only useful in the context of the existing stock and so use the term knowledge to refer to both stocks and flows of knowledge. Information refers just to flows.

Degree of specialization of knowledge affects both knowledge transfer costs and control costs. By definition, knowledge transfer costs are high when knowledge is specialized. Also by definition, specialized knowledge is unobservable by the CEO. This additional "noise" makes it harder to separate the manager's ability and effort from the effects of the state variable. It is more difficult for the CEO's office to assess unit managers' decisions that are based on specialized knowledge. Hence, the costs of controlling unit managers are higher for firms that generate more specialized knowledge. This reduces the tendency for firms generating relatively more specialized knowledge to be more decentralized. We therefore conduct two tail tests on degree of specialization of knowledge.

To estimate whether knowledge in an industry is specialized we identify six factors that we argue are related to transfer costs: ability to automate decisions that use the knowledge; ability to aggregate the knowledge; the level of technology and the extent of change in technology in the industry; level of competition in the industry; the demand for product heterogeneity in the industry; and the amount of uncertainty in the industry. Those factors are attributes of knowledge in the industry or attributes of the industry's market. Based on the first five of those factors we classify industries defined by two-digit SIC codes. That classification is used to generate two knowledge type measures. The sixth factor, uncertainty, is used to generate a third knowledge type measure.

The classification of industries and the resultant information type measures are subjective, but the classification is made "a priori." To test the robustness of our classification, in future versions we will have outsiders who do not know the objective of the research classify the industries using the five factors. We also will attempt to generate objective measures of some of those five factors. In this version, we estimate the relation between decentralization and investment

4 Demsetz' (1988) interest is in how specialized knowledge helps to determine the boundaries of the firm rather than in how decision rights are allocated within the firm, but we interpret Demsetz' term specialized to be knowledge that is costly to transfer. Demsetz does not discuss other types of knowledge. Kaplan and Atkinson (1989) discuss knowledge transfer costs and control costs and also use the term specialized to describe knowledge that is costly to transfer. Because knowledge that is specific to time ar" Jlace is costly to transfer, Jensen and Meckling (1992) adopt the term specific to refer to knowledge :hi is costly to transfer and use the term general to describe knowledge that is not costly to transfer. Since the term specific is used to refer to assets or human capital that lose value if not used in the firm, we use Demsetz' term specialized. 
set characteristics using all three knowledge type measures and using the objective uncertainty measure only.

\subsection{Factors related to knowledge type}

a) Ability to automate decision making. Assembled knowledge is produced by assembling and analyzing knowledge of particular circumstances and is important to the existence and organization of firms (Jensen and Meckling, 1992). Assembled knowledge can be either specialized or non-specialized. When knowledge is assembled as the result of experience it tends to be specialized. A lathe operator develops knowledge over time about operating characteristics of the machine that are difficult to communicate to others. An arbitrageur develops intuition and judgment that are costly to communicate to someone who does not continually observe information flow and the evolution of prices. Inability to automate the decision making process is the crucial ingredient in these examples that makes the assembled knowledge specialized. If decisions can be automated, then the knowledge on which they are based is non-specialized.

On the surface, improvements in computer systems seem to provide the ability to move more knowledge up to decision makers at lower costs. However, a firm's ability to do this is limited by humans' ability to comprehend the data transferred. Automation of decisions requires more than just moving the data observed by say the arbitrageur. Automation must also capture the skill and judgment the arbitrageur develops over time. Expert systems and neural networks are attempts to automate human skill and judgment that is costly to acquire. Since ability to automate decisions changes with technology, organizational form also changes with technology.

b) Ability to aggregate knowledge. When knowledge can be aggregated, it tends to be non-specialized. Further, since non-specialized knowledge can be created by aggregation, it is possible for transfer "costs" to be negative. There can be a net benefit. For example, it is difficult for the owner of one retail store to determine buying patterns or demand trends. Aggregating across related stores can filter out the noise so that trends can be estimated. There is an information externality among stores. Horizontal integration mitigates this externality problem and enables the assembly of cross-sectional knowledge through aggregation. ${ }^{5}$ In a similar fashion, wholesalers learn about demand trends from the orders placed by independent retailers. In contrast to retail chains and wholesalers, which are an example of the assembly of cross-sectional

5 Aggregation of sales data and later dissemination of the aggregated data could be done by a service a $\varepsilon^{-}$t outside the firm. However, individual stores may be reluctant to release such knowledge to an agent 注 ise it helps competitors or entrants and reduces the store's value. Horizontal integration may also reflect scale economies in purchasing and systems development or the value of establishing homogeneity in product quality. 
knowledge, boutiques are attempts to capture the value of information about customer specific preferences.

On the surface it appears that insurance and financial services firms produce both aggregated (non-specialized) and specialized knowledge. Insurance companies produce knowledge on average mortality and accident rates, but they also produce knowledge on the accident rates of specific individuals. However, the knowledge about individuals is easily transferred and so does not meet the definition of specialized knowledge. Further, the essence of insurance is the pooling of risks based on assembled knowledge. In a similar fashion, financial service companies generate data on individual and average default rates as well as individual deposits and withdrawals. The data on individuals is easily transferred via credit reports and is, therefore, non-specialized knowledge. Knowledge of aggregate cash flows is valuable in asset management, so knowledge is created via the aggregation and transfer of individual transactions. Transport, communications and utility networks are other instances where there is assembly of knowledge.

c) Technology and changes in technology. Technical knowledge is difficult to transmit. One cannot simply hand someone a physics, chemistry, engineering or accounting book and have them be experts in these subjects. Even knowing the theory does not guarantee that someone can apply the knowledge to decisions. A famous example that is similar in spirit to those of the machine operator and arbitrageur is the expert pool (or billiards) player; see Friedman (1953, p. 22). While the pool balls obey principles of physics, knowledge of the physical principles is insufficient to make an expert pool player.

In a firm with highly technical production processes that are changing rapidly and are fully understood only by people who work with then every day, the further someone rises in the firm the further they are removed from knowledge of the technology. A CEO who rises through the ranks will understand the technology better than a CEO brought in from another industry, but will still know less about the production than experts lower in the hierarchy. ${ }^{6}$ At each higher level in the organization, technical knowledge is a subset of that at lower levels. Any firm with technical production processes tends to be of this type. Lathe operators and product design engineers develop knowledge over time that is difficult to convey to others.

Organizational design is not static and evolves through time. Technology is important in understanding what knowledge is specialized and what is non-specialized (can be easily transferred) at a point in time. Assembly of knowledge by transport networks is one example. When communications are non existent (or poor), knowledge of a particular half-filled tramp

6 This is one potential explanation for mosı CEOs being internal promotions. 
steamer and its circumstances (its location, capacity, etc.), is specialized knowledge. The only person who can exploit the knowledge is the captain of the steamer. As communications improve, a firm (or agent) can assemble knowledge on half-filled tramp steamers and goods to be noved to decide whether to delegate someone to take advantage of the knowledge. Changes in technology can both convert specialized to non-specialized knowledge and lead to assembly of knowledge. Changes in technology can lead to the creation of firms and affect their organization.

d) Competition. Demand for speed in decision making (immediacy) causes knowledge to be specialized. Immediacy is a function of competition. Machines out of tolerance and arbitrage opportunities are examples where there is value to inmediacy; knowledge is valuable only at a specific time and place. Failure to adjust the machine immediately leads to wasted labor and materials and potential damage to the machine. Stopping the machine avoids these costs, but does not avoid an opportunity loss of output. With competition, failure to act on an arbitrage opportunity immediately leads to loss of the opportunity. Any delay in acting on the knowledge destroys (or reduces) its value. Transfer costs can arise from either physical transmission delays or from the inability of the decision maker to whom the information is transferred to comprehend and act on the knowledge in a timely manner. Such knowledge is specific to time and place and cannot be aggregated without destroying its value. The average arbitrage opportunity or the average deviation of machines from specification is zero.

e) Demand for product heterogeneity. The degree of specialization of a firm's knowledge depends on demand for product heterogeneity across customers. Product heterogeneity can be induced by geographic dispersion of the firm's operations. Automobiles in different countries need to satisfy different safety and emission regulations, cope with different road and temperature conditions, account for different fuel costs and perhaps cater to different tastes. Knowledge of local customs, conditions, regulations and preferences is often costly to acquire and costly to transmit to others not familiar with the conditions.

In contrast to products that vary across regions, consider a firm that produces shovels and forks for gardening. There are a limited number of shovel and fork types and most types are used in a wide variety of conditions. While snow shovels are only used in some regions, this knowledge is easily acquired and transferred. Shovel and fork production is not technologically complex.

Automobiles provide an example where a product is tailored to sub-groups of customers and the knowledge required to do this is costly to transfer. Shovel and fork production does not require detailed knowledge of individual customers or groups of customers, or that knowledge is easily $\operatorname{trn}^{n}$,ferred. Ceteris paribus, one should expect automobile firms to be more decentralized than shovel firms. 
f) Uncertainty. Changing conditions in the firm's product and input markets cause knowledge to be more specialized. The quantity of information increases when the environment is changing rapidly, and delays in acting on information can cause that knowledge to become obsolete. Increased obsolescence rates and increases in information flow increase the specialization of knowledge. For this purpose it does not matter whether the change in the environment comes from the production side (e.g. technological changes) or the denand side (e.g. changes in tastes). 7

\subsection{Measures of knowledge type}

a) Average knowledge specialization. Our classification of two digit SIC code industries is given in table 1. Industries classified as generating relatively more specialized knowledge are coded as having knowledge type one, those classified as generating relatively more non-specialized knowledge are coded as zero and those coded as producing mixed non-specialized and specialized knowledge are coded one-half.

We argue in section 3.1.1 that retail chains and wholesalers learn about demand trends from assembling data and that data is non-specialized. While it is possible for a salesperson to generate specialized knowledge about a customer's preferences, this is more likely to occur in "boutique" operations where there is a high incidence of salesperson-specific repeat business. This is less likely with retail chains which are the type of retail firms in our sample. Exploitation of customer specific knowledge is a likely explanation for the existence of boutiques. Wholesale firms supplying retail firms can also assemble knowledge on demand trends. We also argue that insurance and financial firms produce primarily non-specialized knowledge at low levels in the firm. Therefore, we classify retail, wholesale, insurance, and finance firms as producing primarily non-specialized knowledge.

In section 3.1.1 we also argue that with modern communications, firms characterized by networks produce knowledge that is easily transferred and the firms gain from the aggregation and assembly of knowledge. Hence, we classify transport and utility firms as producing relatively less specialized and relatively more non-specialized knowledge.

7 Growth options are one manifestation of envirommental change. In mature firms with few growth opportunities, demand and cost functions are likely to be well-known and stable. Knowledge of those functions can be transferred to top management at relatively low cost. In growth firms, however, information on deinand and cost conditions is likely to be arriving more frequently (e.g. as new in' ' tments are made and as the demand for the new product is revealed) and be more time specific. If $:$ : $:$ ledge of the opportunities presented by growth options resides at the second level or lower in the organization, the existence of growth options (i.e. opportunities to invest at above the competitive rate of return) causes knowledge to be more specialized. 
We expect firms with physical production processes, such as those in manufacturing, agriculture, mining and construction to generate relatively more specialized knowledge. There is less gain from assembly of knowledge in these industries relative to the technical knowledge that is costly to transfer. ${ }^{8}$ We also expect these industries to have relatively more product heterogeneity and decisions that are harder to automate. Therefore, with two exceptions, we classify all primary production (agriculture, forestry, fishing and mining), construction and manufacturing industries as producing relatively more specialized knowledge. The exceptions are industries related to residential home construction. Large- scale builders of homes ("general building contractors" in table 1) probably gain some assembled knowledge about consumer demand and so we classify that industry as "mixed". The "construction: special trade" industry in table 1 is involved in some residential home construction and so is also classified as "mixed."

Compared with other industry groupings, there is a great deal of variation within the service industries (SIC codes 7000 through 8999) that precludes categorizing the broad group as producing primarily specialized or non-specialized knowledge and so those industries are classified as " mixed." Security and commodity brokers can produce both non-specialized and specialized knowledge (arbitrage opportunities) and so are also classified as "mixed."

The knowledge type (KT) variable for a firm is calculated as the average degree of specialization of knowledge for all four-digit industries listed for the firm. The four-digit industries in which firms are engaged are obtained from Standard and Poor's Register and Dun's Million Dollar Directory. Each four-digit industry is given a score based on table 1's two-digit classification.

b) Incremental specialization from multiple lines of business. When the skills needed to run a particular business are costly to transmit, then firms that own more than one business will effectively produce specialized knowledge at the second level. This can cause the firm to decentralize, even when each line of business produces non-specialized knowledge. It is an empirical matter whether the degree of specialization of the knowledge produced within each of a firm's lines of business or the specialized knowledge needed to run given lines of business dominates organizational design at the second level.

For example, consider an insurance firm that writes say automobile, product liability, marine and general casualty, and life insurance. We argue that each of these insurance businesses generates primarily non-specialized knowledge, yet the knowledge required to manage each of these lines of business may be highly specialized.

8 A similar argument is made by Melumad, Mookherjee and Reichelstein (1992). 
Our knowledge type variable (KT) reflects the average degree of specialization within each of a firm's lines of business. We also have to measure the incremental effect on specialization of specialized knowledge required to run each line of business. We expect that this incremental effect increases with the number of lines of business the firm owns, and is largest for firms that produce primarily non-specialized knowledge within each line of business.

To capture the incremental effect on specialization of multiple lines of business, first define NLOB as the number of lines of business (four digit industries) a firm operates and MAXLOB as the maximum number of lines of business for any firm in the sample. Second, define the standardized number of lines of business (SNLOB) as NLOB/MAXLOB. SNLOB and KT both vary from zero to one. Finally, define $\triangle K T$ as $\operatorname{SNLOB}(1-K T)$, where the $\Delta$ indicates that this effect is incremental. $\Delta \mathrm{KT}$ is increasing in the number of lines of business a firm has and is largest when the firm generates primarily non-specialized knowledge within each line of business. We predict that $\triangle \mathrm{KT}$ and $\mathrm{KT}$ have the same sign.

c) Uncertainty. Changing conditions in the firm's product and input markets affect the volatility of cash flows and this in turn is reflected in the volatility of the rate of return. Ideally we would like to observe the standard deviations (volatilities) of individual divisions, since it is these volatilities that affect whether knowledge can be transferred to the CEO from the second level managers. The volatility of the rate of return on the firm reflects diversification across lines of business. Ceteris paribus, more lines of business (divisions) implies lower volatility. While firm volatility is an increasing function of divisional volatilities, it is a decreasing function of the number of divisions. We therefore measure uncertainty in two steps.

First, we estimate the volatility of the rate of return on equity. Ideally we would unlever the equity volatility to calculate the underlying variance of the rate of return on the firm. Christie $(1982,1989)$ finds that the adjustment to unlever risky debt varies with leverage and that most of the cross-sectional variation in equity return variance is due to variation in firm retum variance. This suggests that using the unlevered variance instead of the equity return variance may increase measurement error rather than reduce it. Hence, we first estimate the volatility (UNC) of the firm's rate of return on equity over the sixty months up to and including December, 1987. ${ }^{9}$

Second, to capture the uncertainty at the divisional level we adjust UNC by the correlations among the firm's lines of business. We call this variable DUNC for divisional uncertainty, and use it as the uncertainty variable in our regressions. The conversion from UNC to DUNC is to divide by $\operatorname{SQRT}\left\{1 / \mathrm{NLOB}+[(\mathrm{NLOB}-1) / \mathrm{NLOB}]^{*} \mathrm{CORR}\right\}$, where NLOB is the number of lines of

9 Uncertainty due to growth increases the variability of the cash flows of the firm and so is captured by this volatility estimate. 
business (industries) the firm is in and CORR is the average off diagonal correlation among the firm's lines of business. ${ }^{10}$ We generate these correlations using industry indices at both the two and three digit SIC level. Our results are not sensitive to the SIC level at which we make this adjustment. We predict DUNC has the same sign as $\mathrm{KT}$ and $\triangle \mathrm{KT}$.

\section{Other Characteristics and Decentralization}

\subsection{Dependence.}

If there are operating and information externalities among the components of a business, complete decentralization does not maximize firm value. Maximization of unit profits by each unit manager does not lead to maximization of firm profits. The vertical integration argument of Klein, Crawford and Alchian (1978) is one example. We call these operating externalities dependencies. They can take the form of dependent demand functions or joint supply or cost functions.

Dependence generates a demand for coordination of the actions of managers of the firm's units. The firm nust induce lower level managers to consider the effects of their decisions on other parts of the firm. More dependent operations require greater coordination by top management and hence lead to larger control costs. In the absence of knowledge transfer costs, the coordination problem can be solved by centralization. In general, therefore, we expect firms with more dependent operations to be more centralized. Conversely, the less dependent the firm's operating units, the more decentralized we expect the firm to be.

Two other sources of dependencies are reputation and product and other tortious liabilities. There are reputation externalities among the divisions of a firm. University administrations (CEOs) delegate decisions about research, course content and hiring untenured faculty to schools and departments, but retain a right of veto over promotion and tenure. Personnel functions are often consolidated at the corporate level to control liabilities associated with anti-discrimination laws. Product testing is often reviewed by corporate legal departments prior to new product introductions.

The operating dependence variable is obtained from the questionnaire, using a question developed by Rumelt (1974) and used by Vancil (1978). Question 8 of the questionnaire asks respondents to classify their firm as being a single business, having a dominant business, having related businesses or having unrelated businesses. The first classification (single business) suggests significant dependencies and is coded four and the last classification (unrelated

10 This adjustment arises because the firm is a portfolio of its component divisions. Volatility of the firm's returns is a function of the average volatility of divisional returns and correlation among the divisions. That is. UNC $=$ DUNC*SQRT $\{1 / \mathrm{NLOB}+[(\mathrm{NLOB}-1) / \mathrm{NLOB}] * \mathrm{CORR}\}$. 
businesses) suggests little dependence and is coded one. Dominant business and related businesses are coded three and two respectively.

The dependent variable (DEC) focuses on line units and so excludes corporate finance, treasury, personnel and legal functions. Therefore, we do not need to include cross-sectional differences in tort exposure in the measure of dependence. In section 6.2 we discuss an alternative measure of dependence that is independent of the questionnaire.

\subsection{Size}

As noted in section 3.1, humans have limited storage and processing capacity. Given that the potential amount of knowledge to be transferred to the CEO increases with firm size, the CEO's limited capacity means that the cost of transferring knowledge to the CEO increases with firm size. Larger firms also have larger control costs, because the increased decentralization increases the cost of the CEO controlling the second level managers. We conduct a two-tailed test of the relation between decentralization and size. The only size variable reported is annual sales, since the results are not sensitive to the altemative size measures available. The sales data are obtained from COMPUSTAT. 11

There is considerable size variation in the sample, but this may not be sufficient if there is a threshold effect with size. If size per se leads to decentralization of decision rights only after the firm reaches a given size, and if most of our firms are larger than this threshold, then continuous measures of size will not capture the important effect of size on decentralization. This also suggests that a dummy variable related to the threshold would be a better size measure than the continuous and categorical variables we use.

\subsection{Regulation}

The regulatory process can affect decentralization. Price regulation is primarily at the firm level and so encourages the firm to transfer knowledge to the top management for regulatory purposes. This reduces the cost of transferring knowledge for other purposes and so encourages regulated firms to be centralized.

There are two difficulties associated with regulation. First, regulation is applied to natural monopolies and so may be endogenous. If monopolies tend to centralize to capture the benefits of monopoly, then regulation is a result of the same factors causing centralization and should not be included as an exogenous variable affecting decentralization. Second, regulation can act as a

11 IVe also use number of employees (EMP). Both categorical variables from the questionnaire and continuous variables from COMPUSTAT are used. With one minor exception, the two data sources are consistent. 
proxy for other factors that determine decentralization of decision rights, knowledge type, uncertainty and dependence.

Regulated industries tend to be industries involving networks where there are gains from the aggregation of knowledge. Hence, regulation serves as a proxy for low knowledge transfer costs, and is likely to be associated with less decentralization. Also, regulatory bodies restrict top management's discretion, including discretion over the type of investments managers can make. This tends to reduce uncertainty and the variance of regulated firms' cash flows (Smith and Watts, 1992). This effect is reinforced by utilities' monopoly position. Utilities do not face uncertainty created by the actions of direct competitors. Consequently, regulation is negatively related to uncertainty and is likely to be associated with less decentralization.

Finally, to the extent that regulators restrict firms to one industry, regulation also is positively related to dependence and again is likely to be associated with less decentralization. Regulation, therefore, acts as a proxy for three other factors associated with less decentralization. All three factor proxy relations suggest regulation is negatively associated with decentralization. These proxy relations do not imply regulation, per se, affects decentralization.

The regulation variable (REG) is defined on an industry basis depending on the primary industry listed for a firm in Dun's Million Dollar Directory. If the primary industry is utility, transportation or communications, the firm is defined as being regulated and its regulatory variable is coded as one. All other firms have their REG variable coded as zero. Since utility, transportation and communications industries are among the industries defined as having low knowledge transfer costs, (see table 1), the regulation variable is negatively correlated with knowledge type. As we argue above, REG is also negatively correlated with uncertainty and positively correlated with dependence.

We estimate the model both with and without a regulation variable. We also check whether the association between the factors (other than regulation) is driven by regulated industries by estimating the model excluding firms in regulated industries

\subsection{Summary of expected empirical relations}

We can summarize the empirical relations developed in sections three and four with the following equation.

$\mathrm{DEC}=\alpha_{0}+\alpha_{1} \mathrm{KT}+\alpha_{2} \Delta \mathrm{KT}+\alpha_{3} \mathrm{DUNC}+\alpha_{4} \mathrm{DEP}+\alpha_{5} \mathrm{SIZE}+\alpha_{6} \mathrm{REG}$

The model (1) requires one dependent and six independent variables. The dependent $v_{i}$ ' ible is the extent of decentralization of decision rights to the firm's second management level (DEC). The predetermined variables are the average type of knowledge generated by a firm's lines 
of business (KT), the incremental effect on specialization of knowledge of multiple lines of business $(\triangle \mathrm{KT})$, the average uncertainty of the firm's investment opportunities at the divisional level (DUNC), the dependence among the firm's investınents (DEP), firm size (SIZE) and whether the firm is regulated (REG). Proxies for DEC and DEP are obtained from the questionnaire. Measures of KT, $\triangle \mathrm{KT}$, DUNC, REG and alternative measures of DEP that we discuss in section 4.3 are obtained from CRSP, COMPUSTAT, Dun's Million Dollar Directory and the Standard \& Poor's Register. SIZE is obtained from both the questionnaire and COMPUSTAT. The questionnaire itself is in appendix $A$. Other basic description of the process associated with the questionnaire is in appendix $B$ and a correlation matrix of the main variables is in appendix $C$.

Equation (1) forms the basis for our empirical work predicting the extent of decentralization. We expect $\alpha_{4}$ and $\alpha_{6}$ to be negative. Increasing dependence increases control costs and leads to less decentralization. Regulation leads to transfer of knowledge upwards for regulatory purposes and thereby lowers the cost of centralization. We expect that $\alpha_{1}, \alpha_{2}, \alpha_{3}$ and $\alpha_{5}$ are non zero. The signs of the coefficients on KT, $\triangle \mathrm{KT}$ and DUNC $\left(\alpha_{1}, \alpha_{2}\right.$, and $\left.\alpha_{3}\right)$ depend on the relative effects of knowledge type on knowledge transfer costs and control costs. If, on average, the partial derivative of knowledge transfer costs with respect to knowledge type is greater than that of control costs, the three coefficients are positive. If the converse is true, all three coefficients are negative. The theory does not necessarily imply a linear relation between decentralization and our explanatory variables. Our approach is to estimate the equation using linear least squares and to test for misspecifications including nonlinearities.

\section{Descriptive Statistics}

This section describes the data and the characteristics of the final sample and provides distributions for the measures used in the empirical work. Details underlying the questionnaire and selection of the sample are in appendix B.

The questionnaire provides evidence on the organization of the firm at the second level. It elicits data on profit and cost centers, dependence among the firm's of investments, and size of the firm. We end up with a usable sample of 121 firms. In relation to the set of COMPUSTAT firms, we obtain a representative size sample. But, utilities, financial and insurance companies are over represented. An extended discussion of potential questionnaire response biases is in appendix B .

Table 2 provides the distributions of the variables used for the 121 firm sample. More than half the firms $(54 \%)$ report that their second level of management is organized into profit centers. The rest of the firms' answers are roughly evenly distributed between organization into cost centers an organization into a mixture of profit and cost centers. The decentralization variable is coded as one for all profit centers, one half for mixed profit and cost centers and zero for all cost centers. 
The type of knowledge (KT) variable is described in section 3.3. It is the average knowledge type over all four digit SIC codes the firm is involved in. Whether or not a firm is involved in an industry or not is determined from the industries listed for the firm in Dun's Million Dollar Directory and in Standard and Poor's Register. The classification of industries into those producing specialized, mixed or non-specialized knowledge is given in table 1. About half the firms (64 out of 121) have their type of knowledge variable coded as all non-specialized (42) or all specialized (22). The mean knowledge type is 0.49 and the median is 0.60 .

The incremental knowledge type $\Delta \mathrm{KT}$ measures the incremental effect of specialized knowledge required to run each line of business within a firm. It ranges from zero to 0.55 with a mean of 0.07. It is increasing in the number of divisions and has a larger partial effect for firms that produce primarily non-specialized information within each line of business. From appendix $C$, $\triangle \mathrm{KT}$ is significantly positively correlated with SNLOB and SIZE, weakly positively correlated with DEC and DUNC, and significantly negatively correlated with KT.

The number of lines of business owned by our sample firms ranges from 1 to 38 with a mean of 8 . So that all our variables and coefficients are approximately on the same scale, we divide NLOB by MAXLOB, the maximum NLOB in our sample of 38 . This scaling also facilitates calculation of $\triangle \mathrm{KT}$ and has no effect on $\mathrm{t}$ statistics or their associated probabilities. It merely scales the coefficients and standards error by the same proportion. The mean standardized number of lines of business (SNLOB) is 0.21 , with a range from 0.03 to 1.0 .

As discussed in section 3.3, divisional uncertainty (DUNC) is measured by the standard deviation of equity return (UNC) adjusted for correlation among the firm's lines of business. A full 60 months is available to estimate UNC for 114 of the 121 firms. The mean number of months over which the standard deviation is estimated for the other seven firms is 35 and the minimum number of months used in the estimation is 21 . In table 2 the mean DUNC is 0.32 and the median is 0.31 . The maximum is 0.72 with a minimum of 0.15 . While these numbers differ only slightly from the corresponding $\mathrm{UNC}$ numbers in table 2, from the correlation matrix in appendix $\mathrm{C}$, one can see that DUNC is more highly correlated with all except the SIZE and REG variables than is UNC.

The distribution of answers to the dependence question in table 2 is $21 \%$ for unrelated businesses, $27 \%$ for related businesses, $23 \%$ for a dominant business and $29 \%$ for a single business. This distribution is similar to the distribution reported by Vancil (1978, p. 154), which is $30 \%, 28 \%, 22 \%$ and $20 \%$ respectively. We have a few more firms in the single business category $\operatorname{ar}^{\prime \prime}$ a few less in the unrelated category than Vancil. This is probably due to the over representation of utilities and banks in our sample. We create dummy variables (DEP2, DEP3 and DEP4) for the last three dependence categories, which are in order of increasing dependence. 
As with SNLOB, the sales numbers obtained from COMPUSTAT are scaled by the maximum of the cross-sectional distribution of sales. The sales data indicate that our 121 firm sample consists of large firms. However, as noted above, the size of firms in the sample is insignificantly different from the size of COMPUSTAT firms that did not respond to the questionnaire. The mean size variable is 0.06 with a median of 0.02 .

The sample includes 28 firms whose primary industry classification is in the utility, communications, transportation or railroads industries, so the mean regulation variable in table 2 is 0.23 and the median is zero. Most regulated firms are utilities (24). Two firms are in the communications industry, one is a railroad and one is a trucking firm.

The means of the variables for the two-digit SIC code industries (using the Dun's Million Dollar Directory primary industries) are given in Table 3 with the industries listed in ascending order in terms of the average decentralization variable. Four industries with few firms in the sample have the maximum mean decentralization (one): agriculture, forestry and fishing; general building construction; heavy construction; and services. Manufacturing, which has the most observations (57), has the next highest average decentralization (.877). The most centralized industries are insurance and real estate (.25) which has only two firms in the sample, and transportation and public utilities (.297) which has 32 firms.

Given the nature of the industries ranked as decentralized and centralized in table 3, it isn't surprising that the mean subjective knowledge type $(\mathrm{KT})$ is significantly positively correlated (at the 0.01 level) with mean decentralization. In addition to mean DEC, mean KT is significantly correlated at least at the 0.10 level with mean dependence (QDEP) and mean SNLOB. Dependence is measured in Table 3 by a continuous variable. Single business responses to the dependence question are coded one, dominant business responses 0.67 , related business responses 0.33 , and unrelated business responses zero. The mean incremental knowledge type variable $(\triangle \mathrm{KT})$ is not significantly correlated at the 0.10 level with any other variable.

In addition to mean $\mathrm{KT}$, mean decentralization is significantly positively correlated (at the 0.025 level) with the mean standardized number of lines of business (SNLOB). None of the other mean variables' correlations with mean DEC are significant at the 0.10 level.

\section{Empirical Relation Between Decentralization and Investment Characteristics}

Theory provides no guidance about the functional form of the relation between decentralization and our explanatory variables. Therefore, we assume linear relations and test for denartures from this assumption. 
The decentralization dependent variable in equation (1) is discrete. Firms either have all profit centers, mixtures of profit and cost centers, or all cost centers. This suggests equation (1) should be estimated using Logit or Probit analysis. However, Noreen (1988) finds that while tests of individual coefficients are well specified using both Probit and ordinary least squares in empirical studies of this nature with this sized sample, Probit's chi-square test of fit rejects the null too frequently. Ordinary least squares' $F$ test on the other hand is reasonably well specified. Stone and Rasp (1991) report similar results for Logit. Hence, we employ ordinary least squares. Least squares also has the advantage that it is easy to generate specification and collinearity diagnostics and to test for nonlinearities.

Three diagnostics are used in all the regressions. The first is a specification test due to White (1980) that can reject if either the regression errors are heteroscedastic or if the errors and explanatory variables are dependent. Since the latter case covers errors in variables, correlated omitted variables, simultaneities and nonlinearities with respect to explanatory variables, this is a general test of specification. 12

The second diagnostic reported is a test for nonlinearities due to Christie (1989). The residuals are sorted by the values of continuous explanatory variables and a Durbin-Watson statistic is calculated for each continuous variable. Nonlinearities are reflected in positively autocorrelated errors. It is assumed that, except for the influence of nonlinearities, the regression errors are cross-sectionally independent.

Third, the Belsley, Kuh and Welsh (1980) collinearity diagnostics are calculated for all regressions. As is evident from appendix $C$, our independent variables are collinear. But, there is no evidence that collinearity is degrading the estimators .

All $\mathrm{R}^{2}$ 's reported in the paper are adjusted for degrees of freedom. Reported probabilities of test statistics are for one tail tests when we predict the sign of an association and two tail otherwise. All significance levels of 0.0001 should be interpreted as less than or equal to 0.0001 .

Given our reservations about exogeneity of the regulation variable, equation (I) is estimated both including and excluding the REG variable and for the unregulated firms only.

12 White also provides a variance/covariance matrix of the coefficient estimators that converges to the .ri variance/covariance matrix in large samples, if the model is well specified. This allows calculation of test statistics that are unbiased, but inefficient, if the White test is detecting heteroscedasticity rather than inisspecification. We discuss this further in section 6.3. 


\subsection{Empirical results}

Column (1) in table 4 contains the results from estimating equation (1) using ordinary least squares and omitting the REG variable. All reported results use the two digit SIC level to adjust UNC to DUNC, since the results are not sensitive to whether we do this at the two or three digit level.

As we expect, the estimated coefficients on the knowledge type variables (KT, $\Delta \mathrm{KT}$ and DUNC) in column (1) are all of the same sign (positive). KT and DUNC are significant at least the 0.003 level and $\triangle \mathrm{KT}$ is significant at the 0.05 level. The positive sign is consistent with knowledge type having a relatively greater effect on knowledge transfer costs than control costs. The coefficient on SIZE is positive and has an associated probability of 0.42 . Each of the dependence dummies has the predicted negative sign with probabilities of $0.375,0.19$ and 0.019 .

The coefficients on DEP2, DEP3 and DEP4 are monotonically decreasing and approximately double from one category to the next in order of increasing dependence. The three coefficients are $-0.03,-0.08$ and -0.21 . We show below that the negative coefficients on DEP2 and DEP3 are robust to different specifications, not withstanding they are not usually statistically significant.

The regression itself is significant at the 0.0001 level and the adjusted $R^{2}$ is 0.45 . The Durbin-Watson statistics indicate there are no nonlinearities with respect to the continuous variables (SIZE and DUNC). We defer further discussion of the specification checks until sections 6.2 and 6.3 .

When the two subjective knowledge type variables (KT and $\Delta \mathrm{KT}$ ) are dropped from the regression (column 2), the coefficient on the remaining knowledge type variable (DUNC) increases (from 0.86 to 1.19 ) and so does the associated $t$ statistic (from 3.00 to 3.96). The coefficients on the dependence dummies and the SIZE variable also become more significant. The coefficients on DEP2, DEP3 and DEP4 are significant at the $0.13,0.013$ and 0.0001 levels respectively and maintain their monotone relation. While the adjusted $\mathrm{R}^{2}$ drops to 0.35 , the regression is still significant at the $0.000 \mathrm{l}$ level. Even without the subjective knowledge type variables and the REG variable there is still a systematic relation between decentralization and investment set characteristics.

Column (3) reports the results of estimating equation (1) including an additive regulation dummy variable. The regulation dummy's coefficient is negative as predicted and significant at the 0.0048 level. The changes of note from columu (I) are that, while the coefficients on SIZE and JL $: \mathrm{C}$ are still positive, the $\mathrm{t}$ statistic on DUNC declines to 1.29 and that on SIZE declines to 0.57 . The coefficients on $\mathrm{KT}$ and $\Delta \mathrm{KT}$ are again positive with probabilities of 0.0006 and 0.061 . 
The coefficients on the dependence dummies are all negative (as predicted), monotonically decreasing as before and of approximately the same significance. As in column (1), the F statistic is significant at the 0.0001 level. Inclusion of REG increases the adjusted $R^{2}$ from 0.45 to 0.48 . The Durbin-Watson statistics indicate no nonlinearity.

The results when the two subjective knowledge type variables are dropped from the regression that includes the regression dummy variable are reported in column (4). Compared to column (3) the probability levels for the coefficients of DUNC, SIZE, and REG fall from 0.20 to $0.173,0.57$ to 0.20 and 0.0048 to 0.0001 respectively (see column (4)).

The correlations of the other variables with regulation predicted in section 4.3 can be seen in the correlation matrix reported in appendix $\mathrm{C}$. The regulation variable is significantly positively correlated with DEP and significantly negatively correlated with KT, DUNC (and UNC) at the 0.0001 level. The correlation with KT occurs because the regulated industries are classified in table $l$ as producing non-specialized knowledge. The correlation with the uncertainty measures is consistent with regulation reducing managerial discretion and hence firm risk, and the correlation with DEP is consistent with regulators restricting firms expansion into other industries.

If $\mathrm{KT}, \triangle \mathrm{KT}$ and DUNC were measured without error, the significant coefficient on regulation indicates that regulation has marginal explanatory powver for decentralization. However, it is likely that REG acts as a proxy for the underlying concepts we are trying to capture with these other variables. It is therefore possible that REG has no marginal explanatory power, notwithstanding its significant negative coefficient. With the data available to us, we have no way to distinguish these possibilities.

To ensure that regulation is not driving the results, we estimate equation (1) using only the 93 firms in unregulated industries. The results are reported in column (5) and are similar to prior columns. All the included variables retain their signs and, except for DUNC, approximate significance levels. The $t$ statistic on DUNC declines to 0.48 . The regression is still significant at the 0.0001 level although the $\mathrm{R}^{2}$ declines to 0.24 . This latter change is not surprising, since elimination of regulated firms removes a great deal of the cross-sectional variation from the sample. The regulated firms tend to produce relatively more non-specialized knowledge, be more dependent and have lower uncertainty.

To test whether the investment set characteristics add anything to the explanation of decentralization over and above knowledge of firms' industries, the regression in column (1) of table 4 is re-estimated with two-digit industry dummy variables added. In the re-estimation the th. dependence dummy variables are replaced by the continuous dependence variable QDEP (see 
section 5). ${ }^{13}$ Because of their limited number of observations, industries 1 and 2 (agriculture, forestry and fishing and mining) are combined in the intercept and industries 3 and 4 (general building construction and heavy construction) are represented by a single dummy variable. As can be seen in table 5, the significance levels for the KT, $\triangle \mathrm{KT}$ and DUNC coefficients fall to 0.16 , 0.12 and 0.10 respectively. The QDEP coefficient is negative as expected and significant at the 0.02 level. The $F$ statistic for the addition of the investment characteristics (KT, $\triangle K T$, DUNC, QDEP and SIZE) is significant at the 0.004 probability level. The F statistic for the industry dummies is not significant at any reasonable probability level. Decentralization is associated with investment set characteristics when industry is controlled.

When the regression in table 5 is repeated with the two subjective knowledge type variables omitted, the significance levels for the coefficients of DUNC and QDEP become 0.07 and 0.001 respectively. The F statistic for the investment characteristics DUNC, QDEP and SIZE is significant at the 0.003 level. There is a systematic relation between the investment characteristics and decentralization even when the subjective knowledge type variables are excluded and industry is controlled. The F statistic for the investment dummies is significant at the 0.0005 level.

Overall the relation of decentralization with knowledge type, incremental knowledge type and dependence is robust. The relation between decentralization and uncertainty is sensitive to inclusion of the REG variable. However, the signs of the partial associations of decentralization with uncertainty and size are robust. While the various specifications estimated are not independent, the signs of the coefficients are always the same, consistent with our predictions and invariant to the particular model. Finally, even without the two subjective knowledge type variables there is a significant relation between investment set characteristics and decentralization.

These statements must be tempered by the knowledge that our regressions are potentially misspecified. Within the linits of the data, we discuss this further in later subsections.

\subsection{Alternative measures of dependence}

The dependence measure is the only explanatory variable obtained from the questionnaire. For two reasons, we explore alternative dependence measures including one that is independent of the questionnaire. First, alternative measures provide evidence about the robustness of our results generally and to the way the question about dependence is asked in particular. The dependence question is intended to capture the existence of production and information externalities within the firm. Our concern is that the dependence question may do nothing more than ask the reverse of the

13 The results reported here are not sensitive to the use of alternative dependence variables DEP4 and DEPLOB introduced in the next section. 
decentralization question. That is, asking whether the firm has related or unrelated businesses might simply be the converse of asking whether it is decentralized (has profit or cost centers). Second, developing a measure of dependence from publicly available sources moves us one step closer to eliminating reliance on the questionnaire and testing the theory on larger and more diverse data sets and in more time periods.

From table 6, the coefficient on DEP4 is approximately twice that on DEP3, four times that on DEP2 and the only one of the three that is consistently statistically significant. This suggests that dependence is most important when the firm considers itself a single business. Therefore, as a first step, we include DEP4 as the only dependence measure in the regression. Therefore, our dependence measure is one if the firm is a single business and is zero otherwise. This regression, which we report in column ( 1 ) of table 6, also includes KT, $\triangle K T$, DUNC. SIZE and REG. The $t$ statistic on DEP4 is -2.18 . The coefficients and $t$ statistics on the other variables are similar to those in the corresponding column (3) of table 6 , as are the adjusted $R^{2}, F$ statistic and DurbinWatson statistic. At least with this sample, the results are robust to dropping DEP2 and DEP3.

We next define a dependence measure that can be obtained from publicly available data. Define DEPLOB as one if all the firm's lines of business fall within a single two digit SIC group and zero otherwise. This is intended to capture the spirit of DEP4 that the firm is a single business. The means of DEP4 and DEPLOB are essentially identical at 0.29 and 0.30 and have a correlation of 0.46 . In relation to DEP4, DEPLOB is more highly correlated with both REG $(0.46$ versus 0.34$)$ and SNLOB (-0.5I versus -0.44). Clearly DEP4 and DEPLOB are related but not identical measures. One potential reason they are not perfectly correlated is that we assign equal weights to all the firm's lines of business. In contrast, we presume that firms give more important lines of business greater weight when answering the questionnaire.

The results of using DEPLOB as the dependence measure are reported in column (2) of table 6. The coefficient on DEPLOB has a $t$ statistic of -2.59 . The results for the other coefficients are similar to column (1). All the coefficients have the same signs and approximately the same significance levels. For all practical purposes the specifications using DEP4 and DEPLOB are the same. We repeat both these specifications for just the unregulated firms and report them in columns (3) and (4). Once again the two variables produce results that are very similar to each other and to column (5) of table 6.

The analysis in table 6 is repeated using DEPLOB calculated at the three digit level (not reported). That is, DEPLOB3 is one if all the firm's SIC codes are within a single three digit group ar' zero othenwise. This variable has a lower correlation with DEP4 than does the corresponding two digit version $(0.36$ versus 0.46$)$. Further, although DEPLOB3 has a negative sign when only unregulated firms are included, it is less significant than both DEP4 and DEPLOB. The coefficient 
on DEPLOB3 is not significantly different from zero when all firms are included. We attribute these differences to the fact that this stronger criterion for interdependence is more sensitive to our equal weighting of all the firm's SIC codes. That is, a firm could have operations in say two different three digit SIC codes within the same two digit classification, but one could be a relatively unimportant part of the firms operations. DEPLOB3 would classify such a firm as not dependent when in fact most of its operations are within the same three digit code and highly dependent. Since firms' disclosures of segment data in annual reports bear no necessary relation to SIC codes, we have no way to weight firms' SIC codes and hence no way to test these conjectures.

We draw two conclusions from table 6. First, our results are robust to different ways of measuring dependence. Second, it is possible to derive a reasonable alternative measure of dependence from publicly available data, notwithstanding that measure equally weights all the firm's SIC codes.

\subsection{Other specification tests}

Misspecification can arise from measurement error, correlated omitted variables, endogeneity of explanatory variables or from coefficients that vary across observations. All our variables are measured with error. SIZE and probably REG are endogenous. Once a firm chooses a line of business, the type of knowledge the firm generates, the types of uncertainties the firm faces and the degree of dependence of the firm's operating units are predetermined. That is, KT, $\triangle K T, D U N C$ and DEP are predetermined when the decentralization decision is made

The asymptotic chi-square statistic due to White (1980) provides a test of the joint hypothesis that a regression model is well specified and homoscedastic. Despite the measurement error and potential endogeneity of some of our explanatory variables, we can reject this joint hypothesis at the $10 \%$ level only for those regressions that exclude the two subjective knowledge type variables (columns 2 and 4 of table 4 ).

Even for the models that are well specified and homoscedastic, it is useful to compare the OLS variance/covariance matrix of the coefficient estimators with the corresponding asymptotic matrix on which the White test is based. The diagonals of the asymptotic variance/covariance matrix are very close to those in the OLS equivalent in all regressions including the two that are misspecified. To the extent that there are small differences between the diagonals, the OLS standard errors tend to be larger than the White asymptotic standard errors. We report all probability levels based on the larger OLS standard errors.

The similarity of the matrices suggests there is no heteroscedasticity in any of the ey.essions. This is interesting in light of our use of OLS with a discrete dependent variable and consistent with the simulations of Noreen (1988) and Stone and Rasp (1991). The minor 
differences between the two matrices are mainly associated with SIZE or variables correlated with SIZE.

The foregoing analysis suggests that further robustness checks with alternative ways to measure SIZE are warranted. We repeat the regressions with a variety of different size measures. These include continuous and categorical variations of sales and number of employees, total assets and SNLOB. From appendix $C$, it is seen that SNLOB is more highly correlated with all the other variables than is our size variable. SNLOB has a correlation with $K T$ of 0.52 , with $\triangle \mathrm{KT}$ of 0.38 and with DUNC of 0.21 . Including SNLOB in the regressions both provides an alternative size measure and checks that our $\mathrm{KT}, \triangle \mathrm{KT}$ and DUNC variables are not just acting as proxies for SNLOB.

When we add SNLOB to the models in columns (3) and (5) of table 4, the results are trivially different from those we report. The largest $t$ statistic we find on SNLOB in any specification is about 0.5 . None of the other size measures leads to results that are markedly different from those in table 4 . The only reason we use sales as the size measure is it typically gives somewhat smaller White statistics.

The weak results we find for size may be due to the nature of our sample. There is considerable size variation in the sample. However, as we discuss in section 4.2 , this variation may not be sufficient if there is a "threshold" effect with size. If size per se leads to decentralization of decision rights only after the firm reaches a given size, and if most of our firms are larger than this threshold, one would not be surprised that we find a weak association between decentralization and size. This also suggests that a dummy variable related to the threshold would be a better size measure than the continuous and categorical variables we use. It is also possible that both knowledge transfer costs and control costs increase with size in such a way that size has little effect on the organization structure. We cannot test these conjectures with our current data.

We also check whether the results are sensitive to measurement of the DUNC variable. All the reported results are repeated with the adjustment for the intra-firm correlation structure calculated at the three-digit level rather than the two-digit level we report. DUNC is also estimated assuming the firm's lines of business are independent and with no adjustment at all. That is, we also use UNC instead of DUNC. None of the results changes in a substantive way.

The results we report in table 4 are robust. None of the alternative specifications we test leads to results that are substantively different from those reported. In particular, there is no evidence that any of our variables are acting as proxies for something like the number of lines of bu ess. Note from columns (1) and (5) in table 4 that, except for DUNC, the slope coefficients are not sensitive to excluding the regulated firms. 
Our REG variable covers utilities, transportation and communications firms. Since financial and insurance firms are also subject to various forms of regulation we rerun the analyses in table 4 including a dummy variable that one is for financial and insurance firms and zero otherwise. This dummy has a $t$ statistic of about -1.0 , but has little effect on the other coefficients and $t$ statistics

\section{Application of the Model to Caterpillar.}

To find an in-sample corporation whose decentralization has been assessed in the media, we searched the Wall Street Journal using the Dow Jones News/Retrieval service for the period 1990 1993 for references to two firms, General Electric and Caterpillar. One of our executive professor colleagues had 'a priori' assessed General Electric as decentralized and Caterpillar as centralized. Using the words "centralized", "decentralized", and "structure", we found references only to Caterpillar.

The independent variables in the model that uses non-questionnaire (column 2 of table 6) are measured in 1987. At that time Caterpillar Inc. was organized on a functional basis which normally implies centralization (Wall Street Journal, 1/30/90, p. B12, "Who's News"). However, also in 1987, faced with competition from abroad (in particular Komatsu), Caterpillar launched its "Plant with a Future Program" to overhaul its factories, installing robots and streamlining assembly systems (see Wall Street Journal, 4/6/90, p. Al, "Currency squeeze: Caterpillar sees gains in efficiency imperiled by strength of dollar"). Later, in 1990, Caterpillar announced "a major reorganization of its management structure designed to push decision-making downward in the organization " (Wall Street Journal, 1/30/90, "Who's News", p. B12). This led to an emphasis on profit centers: "To achieve a 'flatter' and more flexible structure, Caterpillar is replacing its function-oriented hierarchy with highly autonomous profit centers and support divisions".

In responding to our 1988 questionnaire, Caterpillar management describe the firm as using both profit and cost-centers, so its decentralization was scored as 0.5 (mixed). The predicted dependent variable for Caterpillar using the estimated equation in column (2) of table 6 is 0.71 . The cut-off values for predicting decentralization, mixed or centralized that are symmetric around 0.5 and minimize the number of misclassifications are 0.72 and 0.28 . At 0.71 Caterpillar would be classified as mixed consistent with the management response, but clearly it is marginal between mixed and decentralized. By 1992 the model implies greater decentralization for Caterpillar. Using 1992 data, the predicted decentralization for Caterpillar is 0.84 . This is primarily due to the dependence variable (DEPLOB) decreasing from one to zero. In 1987 all of Caterpillar's lines of bi ness fall within the same two digit group (SIC two-digit code 35 - machinery except electrical); in 1992 they do not. The new lines of business are concrete products (except block and brick - SIC 
four digit code 3272), short-term business credit institutions (6153), accident and health insurance (6321) and fire, marine and casualty insurance (6331). Whether the added lines of business are a cause or an effect of the organizational change is an issue we are pursuing. Note that the implications of the model excluding the subjective knowledge type variables for Caterpillar's decentralization in 1987 and 1992 are essentially the same as those reported here.

The Caterpillar case suggests that the model is working as implied in the more aggregate results, but it requires more exploration (e.g., the reasons for the addition of the new industries). Further, additional cases may provide further intuition and insight. On that point, we note that the expected decentralization for General Electric in both 1987 and 1992 using the model in column (2) of table 4 is 0.89 . GE's management reported in the 1988 questionnaire that all the units at the second level are organized as profit centers so GE's decentralization variable is scored as 1.0.

\section{Summary And Conclusions}

We expand on the analysis and evidence in Jensen and Meckling (1992), Chandler (1962 and 1977), Vancil (1978) and Williamson (1975) to provide evidence that decentralization of the firm is robustly related to characteristics of the firm's investment opportunity set. Those characteristics are the type of knowledge generated in the firm's industry, the dependence of the firm's investments, firm size and regulation. Evidence on the association between decentralization and these variables is generated using a questionnaire and data from public sources.

The evidence is consistent with the expected associations. The empirical associations are generally significant and always have the same signs across different specifications. We predict the signs of two variables' associations with decentralization (dependence and regulation). The sign of the association of decentralization with the other variables depends on the relative effects of these variables on knowledge transfer costs and control costs. However, the coefficients on the three variables that measure knowledge type should have the same sign. The evidence is consistent with all these predictions.

The evidence is consistent with knowledge transfer costs being, on average, relatively more important than control costs in the decentralization decision. More decentralized firms tend to generate more specialized knowledge, have lower dependencies among the firms' investments and have greater uncertainty about the firms' returns. They are also tend to be larger and unregulated. The evidence not only supports the predicted associations between decentralization and other variables, but also it is robust. There is no evidence of nonlinearity with respect to the continuous independent variables and the coefficients are robust to excluding some of the firms and to different $w_{i}:$ of measuring variables. Except for the models that exclude the two subjective knowledge type variables, we cannot reject the hypothesis that our models are well specified and 
homoscedastic, despite the fact that our independent variables are mismeasured, and some of the explanatory variables are endogenous.

An important caveat that indicates the nature of the endogeneity has to do with the acquisition of knowledge. We argue that the allocation of decision rights depends on the type of knowledge generated by the firm. However, allocating decision rights to someone might change the nature of the knowledge they acquire. In particular, they might acquire more or different knowledge from that acquired in the absence of the decision rights. Further, as noted in the Caterpillar case, decentralization of decision rights can change the degree of dependence of the firms' investments. While we speculate that these are second order effects, we have no way of testing this. 14

Two of our three measures of knowledge type depend on a subjective classification. While subjective, it is made a priori and we believe it reflects Jensen and Meckling's notions of specialized, assembled and non-specialized knowledge. Further, a robust relation exists between decentralization and the other investment set characteristics when the two variables are dropped.

The data obtained from our questionnaire enable us to investigate other theory of the firm issues in future papers. In particular, we plan to draw on the analysis in this paper and other data in the questionnaire and investigate variation across firms in methods used for transfer pricing, budgeting, and performance measurement and evaluation. Variation in the use of accounting numbers in these processes is an integral part of the future work.

14 Endogeneity is one explanation for the collinearity among explanatory variables we observe in appendix $\mathrm{C}$. 


\section{Table 1}

\section{Classification of Industries by Knowledge Type}

\begin{tabular}{|c|c|c|c|c|}
\hline $\begin{array}{c}\text { Group } \\
\text { Number }\end{array}$ & SIC codes & Industry & $\begin{array}{c}\text { Knowledge } \\
\text { Type }\end{array}$ & Code \\
\hline 1 & $0100-0999$ & Agriculture, Forestry \& Fishing & Specialized & 1.0 \\
\hline 2 & $1000-1499$ & Mining & Specialized & 1.0 \\
\hline 3 & $1500-1599$ & Construction: General Building & Mixed & 0.5 \\
\hline 4 & $1600-1699$ & Construction: Heavy & Specialized & 1.0 \\
\hline 5 & $1700-1799$ & Construction: Special Trade & Mixed & 0.5 \\
\hline 6 & $1800-1999$ & Unused & & \\
\hline 7 & $2000-3999$ & Manufacturing & Specialized & 1.0 \\
\hline 8 & $4000-4999$ & Transportation \& Public Utilities & Non-specialized & 0.0 \\
\hline 9 & $5000-5199$ & Wholesale Trade & Non-specialized & 0.0 \\
\hline 10 & $5200-5999$ & Retail trade & Non-specialized & 0.0 \\
\hline 11 & $6000-6199$ & Finance & Non-specialized & 0.0 \\
\hline 12 & $6200-6299$ & Security and Commodity Brokers & Mixed & 0.5 \\
\hline 13 & $6300-6999$ & Insurance and Real Estate & Non-specialized & 0.0 \\
\hline 14 & $7000-8999$ & Services & Mixed & 0.5 \\
\hline 15 & $9000-9999$ & Government and Public Administration & Mixed & 0.5 \\
\hline
\end{tabular}




\section{Table 2}

\section{Empirical Distributions of Variables ${ }^{\#}$ 121 firm sample, 1987 data.}

Panel A: Variables from the questionnaire:

\begin{tabular}{lcccc} 
Decentralization (DEC) & $\begin{array}{c}\text { Cost } \\
\text { Centers }\end{array}$ & Mixed & $\begin{array}{c}\text { Profit } \\
\text { Centers }\end{array}$ & Total \\
\hline & 25 & 30 & 66 & 121 \\
Coded & $(21 \%)$ & $(25 \%)$ & $(54 \%)$ & \\
& 0 & 0.5 & 1.0 &
\end{tabular}

\begin{tabular}{lccccc} 
Dependence (DEP) & $\begin{array}{c}\text { Unrelated } \\
\text { Businesses }\end{array}$ & $\begin{array}{c}\text { Related } \\
\text { Businesses }\end{array}$ & $\begin{array}{c}\text { Dominant } \\
\text { Business }\end{array}$ & $\begin{array}{c}\text { Single } \\
\text { Business }\end{array}$ & Total \\
\hline & 25 & 33 & 28 & 35 & 121 \\
Coded & $(21 \%)$ & $(27 \%)$ & $(23 \%)$ & $(29 \%)$ & \\
& 1 & 2 & 3 & 4 &
\end{tabular}

Panel B: Variables as analyzed

\section{Decentralization (DEC)}

Knowledge type (KT)

Average knowledge type for the firm's

SIC codes (lines of business)

Standardized number of lines of business (NLOB/MAXLOB)

Incremental knowledge type $(\Delta K T)$ $\operatorname{SNLOB}(1-\mathrm{KT})$

Uncertainty (UNC)

Divisional uncertainty (DUNC)

Lines of business dependent

Sales (SIZE)

Sales divided by the maximum sales.

Regulation (REG)

One if the firm's principal business is regulated, zero otherwise.*

\begin{tabular}{ccccc} 
Min & Mean & Median & Max & Std Dev \\
\hline 0.00 & 0.67 & 1.00 & 1.00 & 0.40 \\
0.00 & 0.49 & 0.60 & 1.00 & 0.41 \\
& & & & \\
0.03 & 0.21 & 0.16 & 1.00 & 0.18 \\
0.00 & 0.07 & 0.05 & 0.55 & 0.07 \\
0.15 & 0.31 & 0.30 & 0.68 & 0.10 \\
0.15 & 0.32 & 0.31 & 0.72 & 0.10 \\
0.00 & 0.06 & 0.02 & 1.00 & 0.13 \\
0.00 & 0.23 & 0.00 & 1.00 & 0.42
\end{tabular}

. . . variable shown as 0.00 may be greater than zero but is less than .005 .

* Utilities, communications and transport firms are considered regulated. 
Table 3

\section{Description of Variables by Industry Groupa}

\begin{tabular}{|c|c|c|c|c|c|c|c|c|c|c|}
\hline $\begin{array}{l}\text { Group } \\
\text { Number }\end{array}$ & Industry & NOBS & DEC: & KT & $\Delta \mathrm{KT}$ & QDEP & DUNC: & SIZE & DREG; & SNLOB \\
\hline 13 & Insurance and Real Estate & 2 & 0.250 & 0.000 & 0.066 & 1.000 & 0.292 & 0.017 & 0.000 & 0.066 \\
\hline 8 & Transportation \& Public Ltilities & 32 & 0.297 & 0.086 & 0.067 & 0.771 & 0.243 & 0.037 & 0.875 & 0.086 \\
\hline 11 & Finance & 8 & 0.500 & 0.010 & 0.074 & 0.625 & 0.344 & 0.014 & 0.000 & 0.076 \\
\hline 10 & Retail trade & 10 & 0.600 & 0.186 & 0.149 & 0.600 & 0.383 & 0.051 & 0.000 & 0.197 \\
\hline 9 & Wholesale trade & 2 & 0.750 & 0.167 & 0.053 & 1.000 & 0.426 & 0.016 & 0.000 & 0.066 \\
\hline 2 & Mining & 3 & 0.833 & 0.714 & 0.088 & 0.333 & 0.318 & 0.171 & 0.000 & 0.298 \\
\hline 7 & Manufacturing & $\$ 7$ & 0.877 & 0.850 & 0.044 & 0.374 & 0.350 & 0.080 & 0.000 & 0.292 \\
\hline 1 & Agriculture, Forestry \& Fishing & 1 & 1.000 & 0.600 & 0.053 & 0.670 & 0.320 & 0.008 & 0.000 & 0.132 \\
\hline 3 & Construction: General Building & 2 & 1.000 & 0.496 & 0.099 & 0.500 & 0.440 & 0.011 & 0.000 & 0.197 \\
\hline 4 & Construction: Heavy & 1 & 1.000 & 0.688 & 0.066 & 0.670 & 0.304 & 0.007 & 0.000 & 0.211 \\
\hline 14 & Services & 3 & 1.000 & 0.459 & 0.189 & 0.110 & 0.365 & 0.030 & 0.000 & 0.360 \\
\hline
\end{tabular}

a $\mathrm{DEC}=$ Decentralization. Equals one if the second level units are all profit centers, zero if they are all cost centers and one-half if there are both profit and cost centers.

$\mathrm{KT}=$ Average knowledge type for the industries in which the firm operates.

$\triangle \mathrm{KT}=$ Incremental knowledge type of multiple lines of business, SNLOB(1-KT)

QDEP $=$ Dependency of business units. QDEP is coded zero, one third, two thirds and one for unrelated businesses, related businesses, dominant business and single business respectively.

UNC $=$ Std. dev. of rate of return on equity for the 60 months ended 12/87.

DUNC $=$ UNC/SQRT $\left\{1 / N L O B+[(N L O B-1) / N L O B]^{*} C O R R\right\}$.

CORR $=$ Average off diagonal correlation among the firm's lines of business at the two digit SIC level.

SIZE $=$ Sales for 1987 as per COMPUSTAT divided by sample maximum sales.

REG = Unity if the firm's primary industry is utility, transportation or communications.

SNLOB $=$ Number of lines of business divided by sample maximum NLOB. 
Table 4

Determinants of Decentralization: Dependent Variable DEC

Sample: 93 unregulated and 28 regulated firms in $1987^{\mathrm{a}}$

\begin{tabular}{|c|c|c|c|c|c|c|}
\hline & $\begin{array}{l}\text { Predicted } \\
\text { Sign }\end{array}$ & $\begin{array}{c}\text { All } \\
\text { Firms } \\
(1) \\
\end{array}$ & $\begin{array}{c}\text { All } \\
\text { Firms } \\
(2) \\
\end{array}$ & $\begin{array}{c}\text { All } \\
\text { Firms } \\
(3) \\
\end{array}$ & $\begin{array}{c}\text { All } \\
\text { Firms } \\
(4) \\
\end{array}$ & $\begin{array}{l}\text { Unregulated } \\
\text { Firms } \\
(5) \\
\end{array}$ \\
\hline Intercept & $?$ & 0.18 & 0.47 & 0.44 & 0.76 & 0.49 \\
\hline$t$ & & 1.39 & 3.78 & 2.84 & 5.72 & 3.23 \\
\hline $\operatorname{Prob}(t)$ & & 0.17 & 0.0002 & 0.0053 & $0.000 \mathrm{l}$ & 0.0018 \\
\hline KT & $?$ & 0.45 & & 0.35 & & 0.39 \\
\hline$t$ & & 4.79 & & 3.52 & & 4.00 \\
\hline $\operatorname{Prob}(t)$ & & 0.0001 & & 0.0006 & & 0.0001 \\
\hline$\Delta \mathbf{K T}$ & $?$ & 0.91 & & 0.84 & & 0.95 \\
\hline$t$ & & 2.00 & & 1.90 & & 2.21 \\
\hline $\operatorname{Prob}(t)$ & & 0.048 & & 0.061 & & 0.03 \\
\hline DUNC & $?$ & 0.86 & 1.19 & 0.42 & 0.45 & 0.15 \\
\hline$t$ & & 3.00 & 3.96 & 1.29 & 1.37 & 0.48 \\
\hline Prob(t) & & 0.0034 & 0.0001 & 0.200 & 0.173 & 0.64 \\
\hline DEP2 & - & -0.03 & -0.10 & -0.04 & -0.09 & -0.02 \\
\hline $\mathrm{t}$ & & -0.32 & -1.13 & -0.46 & -1.18 & -0.23 \\
\hline $\operatorname{Prob}(t)$ & & 0.375 & 0.13 & 0.32 & 0.12 & 0.41 \\
\hline DEP3 & - & -0.08 & -0.21 & -0.07 & -0.16 & -0.07 \\
\hline$t$ & & -0.88 & -2.26 & -0.81 & -1.80 & -0.80 \\
\hline $\operatorname{Prob}(t)$ & & 0.19 & 0.013 & 0.21 & 0.037 & 0.21 \\
\hline DEP4 & - & -0.21 & -0.47 & -0.20 & -0.38 & -0.13 \\
\hline $\mathrm{t}$ & & -2.11 & -5.48 & -2.11 & -4.55 & -1.34 \\
\hline $\operatorname{Prob}(t)$ & & 0.019 & 0.0001 & 0.037 & 0.0001 & 0.09 \\
\hline SIZE & $?$ & 0.18 & 0.42 & 0.13 & 0.28 & 0.11 \\
\hline$t$ & & 0.80 & 1.80 & 0.57 & 1.29 & 0.53 \\
\hline $\operatorname{Prob}(t)$ & & 0.42 & 0.075 & 0.57 & 0.20 & 0.60 \\
\hline REG & - & & & -0.25 & -0.36 & \\
\hline$t$ & & & & -2.88 & -4.34 & \\
\hline $\operatorname{Prob}(t)$ & & & & 0.0048 & 0.0001 & \\
\hline Adjusted $\mathrm{R}^{2}$ & & 0.45 & 0.35 & 0.48 & 0.43 & 0.24 \\
\hline F statistic & & 14.92 & 13.70 & 14.93 & 16.35 & 5.21 \\
\hline Prob (F) & & 0.0001 & 0.0001 & 0.0001 & 0.0001 & 0.0001 \\
\hline Durbin-Watson (SIZE) $)^{b}$ & & 1.90 & 1.88 & 1.97 & 2.05 & 2.03 \\
\hline Prob(White Statistic) & & 0.46 & 0.013 & 0.50 & 0.053 & 0.44 \\
\hline Prob(DEP2=DEP3=DEP4) & & 0.12 & 0.0001 & 0.15 & 0.001 & 0.44 \\
\hline
\end{tabular}




\section{Table 4 (continued)}

a $\mathrm{DEC}=$ Decentralization. Equals one if the second level units are all profit centers, zero if they are all cost centers and one-half if there are both profit and cost centers.

KT $=$ Average knowledge type for the industries in which the firm operates.

NLOB $=$ Number of lines of business (4 digit SIC codes) the firm operates in.

SNLOB $=$ Number of lines of business divided by sample maximum NLOB.

$\triangle \mathrm{KT}=$ Incremental knowledge type of multiple lines of business, SNLOB( I-KT)

UNC $=$ Std. dev. of rate of return on equity for the 60 months ended 12/87.

DUNC $=$ UNC/SQRT $\left\{1 / N L O B+[(N L O B-1) / N L O B]{ }^{*}\right.$ CORR $\}$.

CORR $=$ Average off diagonal correlation among the firm's lines of business at the two digit SIC level.

DEPi = Dependency of business units. DEP2, DEP3 and DEP4 are coded one for related businesses, dominant business and single business, and zero otherwise.

SIZE $=$ Sales for 1987 as per COMPUSTAT.

REG = Unity if the firm's primary industry is utility, transportation or communications.

b The Durbin-Watson statistic with the residuals sorted by size. This is a test for nonlinearity. The Durbin-Watson when the residuals are sorted by the uncertainty variable is similar to those reported by size. 
Table 5

Determinants of Decentralization: Theory Versus Industry Dummies Sample: 93 unregulated and 28 regulated firms in $1987^{\circ}$

\begin{tabular}{|c|c|c|c|}
\hline & $\begin{array}{c}\text { Predicted } \\
\text { Sign } \\
\end{array}$ & $\begin{array}{l}\text { All Firms } \\
\text { (1) }\end{array}$ & $\begin{array}{c}\text { All Firms } \\
\text { (2) }\end{array}$ \\
\hline Intercept & $?$ & 0.54 & 0.77 \\
\hline t & & 2.29 & 4.12 \\
\hline KT & $?$ & 0.24 & \\
\hline$t$ & & 1.43 & \\
\hline$\Delta K T$ & $?$ & 0.76 & \\
\hline$t$ & & 1.57 & \\
\hline DUNC & $?$ & 0.53 & 0.57 \\
\hline$t$ & & 1.67 & 1.81 \\
\hline QDEP & - & -0.21 & -0.28 \\
\hline$t$ & & -2.21 & -3.24 \\
\hline SIZE & $?$ & 0.20 & 0.30 \\
\hline$t$ & & 0.91 & 1.45 \\
\hline IND4 & $?$ & 0.16 & 0.15 \\
\hline$t$ & & 0.71 & 0.68 \\
\hline IND7 & $?$ & -0.03 & -0.01 \\
\hline $\mathrm{t}$ & & -0.17 & -0.08 \\
\hline IND8 & $?$ & -0.29 & -0.41 \\
\hline $\mathrm{t}$ & & -1.58 & -2.49 \\
\hline IND9 & $?$ & 0.11 & 0.01 \\
\hline $\mathrm{t}$ & & 0.39 & 0.04 \\
\hline IND10 & $?$ & -0.19 & -0.24 \\
\hline $\mathrm{t}$ & & -0.99 & -1.33 \\
\hline IND11 & $?$ & -0.16 & -0.30 \\
\hline$t$ & & -0.75 & -1.61 \\
\hline IND13 & $?$ & -0.29 & -0.41 \\
\hline$t$ & & -1.05 & -1.56 \\
\hline IND14 & $?$ & 0.32 & 0.45 \\
\hline t & & 1.10 & 1.61 \\
\hline Adjusted $\mathrm{R}^{2}$ & & 0.46 & 0.45 \\
\hline F statistic $(K T=\Delta K T=D U N C=Q D E P=S I Z E=0)$ & & 3.70 & \\
\hline F statistic $(\mathrm{DUNC}=\mathrm{QDEP}=\mathrm{SIZE}=0)$ & & & 4.99 \\
\hline Prob (F) & & 0.004 & 0.003 \\
\hline F statistic (All Industry Dummies = Zero) & & 1.14 & 3.86 \\
\hline Prob (F) & & 0.34 & 0.0005 \\
\hline Prob(White Statistic) & & 0.94 & 0.65 \\
\hline
\end{tabular}




\section{Table 5 (continued)}

a $\mathrm{DEC}=$ Decentralization. Equals one if the second level units are all profit centers, zero if they are all cost centers and one-half if there are both profit and cost centers.

KT = Average knowledge type for the industries in which the firm operates.

NLOB $=$ Number of lines of business (4 digit SIC codes) the firm operates in.

SNLOB = Number of lines of business divided by sample maximum NLOB.

$\Delta \mathrm{KT}=$ Incremental knowledge type of multiple lines of business, SNLOB(1-KT)

UNC $=$ Std. dev. of rate of return on equity for the 60 months ended 12/87.

DUNC $=\mathrm{UNC} / \mathrm{SQRT}\left\{1 / \mathrm{NLOB}+[(\mathrm{NLOB}-1) / \mathrm{NLOB}]^{*} \mathrm{CORR}\right\}$.

CORR $=$ Average off diagonal correlation among the firm's lines of business at the two digit SIC level.

QDEP = Dependency of business units. QDEP is coded zero, one third, two thirds and one for unrelated businesses, related businesses, dominant business and single business respectively.

SIZE $\quad=\quad$ Sales for 1987 as per COMPUSTAT.

REG = Unity if the firm's primary industry is utility, transportation or communications.

b The Durbin-Watson statistic with the residuals sorted by size. This is a test for nonlinearity. The Durbin-Watson when the residuals are sorted by the uncertainty variable is similar to those reported by size. 
Table 6

Determinants of Decentralization: Dependent Variable DEC

Alternative Measures of Dependence

Sample: 93 unregulated and 28 regulated firms in $1987^{a}$

\begin{tabular}{|c|c|c|c|c|c|}
\hline & $\begin{array}{l}\text { Predicted } \\
\text { Sign }\end{array}$ & $\begin{array}{c}\text { All } \\
\text { Firms } \\
(1)\end{array}$ & $\begin{array}{l}\text { All } \\
\text { Firms } \\
(2) \\
\end{array}$ & $\begin{array}{c}\text { Unregulated } \\
\text { Firms } \\
\text { (3) } \\
\end{array}$ & $\begin{array}{c}\text { Unregulated } \\
\text { Firms } \\
(4) \\
\end{array}$ \\
\hline Intercept & $?$ & 0.40 & 0.46 & 0.45 & 0.49 \\
\hline$t$ & & 2.83 & 3.16 & 3.31 & 3.48 \\
\hline $\operatorname{Prob}(t)$ & & 0.0055 & 0.002 & 0.0013 & 0.008 \\
\hline KT & $?$ & 0.37 & 0.32 & 0.40 & 0.38 \\
\hline $\mathbf{t}$ & & 3.92 & 3.27 & 4.35 & 3.95 \\
\hline $\operatorname{Prob}(t)$ & & $0.000 \mathrm{I}$ & 0.0001 & 0.001 & 0.002 \\
\hline$\Delta \mathbf{K T}$ & $?$ & 0.92 & 0.71 & 1.00 & 0.87 \\
\hline$t$ & & 2.16 & 1.61 & 2.41 & 2.03 \\
\hline $\operatorname{Prob}(t)$ & & 0.033 & 0.11 & 0.18 & 0.045 \\
\hline DUNC & $?$ & 0.40 & 0.35 & 0.14 & 0.10 \\
\hline$t$ & & 1.27 & 1.11 & 0.46 & 0.33 \\
\hline $\operatorname{Prob}(t)$ & & 0.21 & 0.27 & 0.65 & 0.74 \\
\hline DEP4 & - & -0.15 & & -0.09 & \\
\hline$t$ & & -2.18 & & -1.24 & \\
\hline $\operatorname{Prob}(t)$ & & 0.016 & & 0.109 & \\
\hline DEPLOB & - & & -0.21 & & -0.14 \\
\hline$t$ & & & -2.59 & & -1.61 \\
\hline $\operatorname{Prob}(t)$ & & & 0.055 & & 0.056 \\
\hline SIZE & $?$ & 0.075 & 0.09 & 0.06 & 0.07 \\
\hline $\mathrm{t}$ & & 0.36 & 0.42 & 0.32 & 0.33 \\
\hline Prob(t) & & 0.72 & 0.67 & 0.75 & 0.74 \\
\hline REG & - & -0.25 & -0.23 & & \\
\hline$t$ & & -2.93 & -2.76 & & \\
\hline $\operatorname{Prob}(t)$ & & 0.002 & 0.0034 & & \\
\hline Adjusted $\mathrm{R}^{2}$ & & 0.49 & 0.49 & 0.25 & 0.26 \\
\hline F statistic & & 20.03 & 20.68 & 7.27 & 7.55 \\
\hline Prob (F) & & 0.0001 & 0.0001 & 0.0001 & 0.0001 \\
\hline Durbin-Watson (SIZE) ${ }^{b}$ & & 1.95 & 1.93 & $2.00^{\circ}$ & 1.93 \\
\hline Prob(White Statistic) & & 0.31 & 0.47 & 0.39 & 0.40 \\
\hline
\end{tabular}




\section{Table 6 (continued)}

a $\mathrm{DEC}=$ Decentralization. Equals one if the second level units are all profit centers, zero if they are all cost centers and one-half if there are both profit and cost centers.

KT $=$ Average knowledge type for the industries in which the firm operates.

NLOB $=$ Number of lines of business (4 digit SIC codes) the firm operates in.

SNLOB $=$ Number of lines of business divided by sample maximum NLOB.

$\Delta \mathrm{KT}=$ Incremental knowledge type of multiple lines of business, SNLOB(1-KT)

UNC $=$ Std. dev. of rate of return on equity for the 60 months ended 12/87.

DUNC $=U N C / S Q R T\left\{1 / N L O B+[(N L O B-1) / N L O B]^{*} \mathrm{CORR}\right\}$.

CORR $=$ Average off diagonal correlation among the firm's lines of business at the two digit SIC level.

DEPi = Dependency of business units. DEP2, DEP3 and DEP4 are coded one for related businesses, dominant business and single business, and zero othervise.

QDEP $=$ Dependency of business units. QDEP is coded one for a single business, 0.67 for a dominant business, 0.33 for related businesses, and zero otherwise.

DEPLOB $=$ Dependency of business units. DEPLOB is coded one if all the firm's

SIZE $=\quad \begin{aligned} & \text { lines of business are within a single } 2 \\ & \text { Sales for } 1987 \text { as per COMPUSTAT }\end{aligned}$

REG = Unity if the firm's primary industry is utility, transportation or communications.

b The Durbin-Watson statistic with the residuals sorted by size. This is a test for nonlinearity The Durbin-Watson when the residuals are sorted by the uncertainty variable is similar to those reported by size 


\section{Appendix A}

\section{Budgeting Function Questionnaire}

Questionnaire \#

Name of the finn:

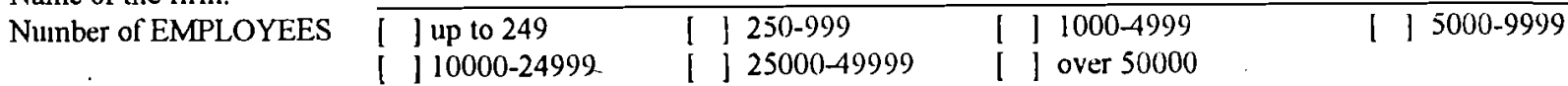

\begin{tabular}{ll}
\hline Anumal SALES (if bank, insurance, real estate or financial companies, cross here & [ ] and give the total ASSETS): \\
$\begin{array}{ll}\text { | ] less than } 15 \text { million } & \text { | ] } 0.015-0.99 \text { billion }\end{array}$ \\
$\begin{array}{ll}\text { [ ] } 2.5-4.99 \text { billion } & \text { | ] over } 5 \text { billion }\end{array}$
\end{tabular}

\begin{tabular}{ll}
\hline Ownership & [ ] publicly-held company
\end{tabular}

Thank you very inuch for participating in this study. Please read the following delinitions carefully:

"line unit" ineans exclusivelv a line level directly reporting to the CEO. The name of that level will vary with its function in the organizational structure and with linn size (e.g., it may be a group, a division or a department). The line unit may or may not be a separate legal entity (subsidiary)

A "line manager" is the person responsible for a line unit.

The expression "CEO" includes the CEO himself, and any inember of CEO's office or corporate staff.

Now please answer each of the following questions. If you want to inake some additional comments, please do so at the end of the questionnaire. Indicate the number of the question that your remark or comment addresses.

1. Is a line manager allowed to substitute one line item of the budget for another on his own initiative?

[ ] No, the budget is never modified during the period

[ ] No, he has to ask for authorization before substitution

[ ] Yes, but only in certain limits and he has to justify it. If the limits are fonnally defined, what are they?

[ ] Yes, as long as the bottom line (line unit's financial objective) is improved

[ ] Other (please specify)

2. Who initiates and who decides the capital expenditures for line units?

[ ] Initiation and decision by $\mathrm{CEO}$, with consultation of line manager (central plauning of investments)

[ ] Initiation by the line manager, decision by $\mathrm{CEO}$

[ ] Initiation by the line manager, decision by the line manager within given limits.

Are limits given:

[ ] in monetary units (how mucli: $\$$
[ ] in percentage (ot what?
[ ] mixed or other method (explain)
[ ] Other (please specify)

3. Do the line managers normally receive incentive compensation in the form of an anumal cash bonus? If yes, what is, on average (last 3 years, for instance), the ratio of cash bonus to anumal salary:

[ ] no bonus system [ ] under $10 \%$ [ ] 11-25\% [ ] 26-50\% [ ] over $50 \%$

4. How, if at all, are the components of the line manager's compensation (salary, bonus and promotion) related to:

- his line unit's financial performance

- the extent to which the budget is met

- the number of years in the company

- the company's overall financial perionmance

- other factors:

\begin{tabular}{|c|c|c|}
\hline salary & bonus & proinotion \\
\hline I & [ ] & 1 \\
\hline [ ] & [ ] & [ ] \\
\hline I I & [ ] & [ ] \\
\hline i 1 & [ ] & [ ] \\
\hline [ ] & [ ] & [ ] \\
\hline
\end{tabular}

Scale: ' very important, major factor

? j important factor

[2] one factor, but not especially important

[1] not important at all

$[\mathrm{X}]$ do not know or not suitable 


\section{Appendix A (continued)}

5. How often are budgeted and actual results compared:

a) by the line managers (for their line unit):

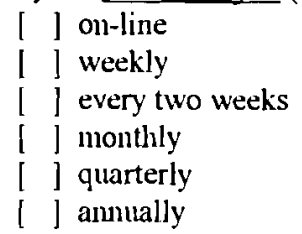

b) by the CEO (for all line units):

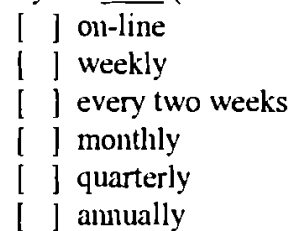
times per year [ ] other:

6. In your company, how important is each of the following budgeting functions?

\begin{tabular}{llll}
\hline Scale: & {$[4]$ essential } & {$[3]$ important } & [2] sometimes useful
\end{tabular}

a) In my firm, budgeting serves to

- set precise individual objectives and control their achievements

- control costs

- evaluate management (compensation)

- motivate and encourage participation of line managers

- facilitate internal communication (between line managers or with CEO)

- establish long range plamuing (2 years or more)

- decentralize the right of decision-making

- forecast the global result of the firm

- set operational plaming (up to 1 year)

- coordinate (line units)

- other (please specify)

b) In your company, what is the budget's general inportance as a management tool?

c) In your company, how important do you think the budget should be?

\begin{tabular}{|c|c|c|c|c|c|}
\hline scale: & 4 & 3 & 2 & 1 & $\mathrm{X}$ \\
\hline ts & [ ] & [ ] & [ ] & 1 & 1 \\
\hline & 11 & 11 & 11 & [ ] & I \\
\hline & I I & [ ] & 11 & 11 & I \\
\hline & [ ] & [ ] & [ ] & [ ] & I \\
\hline with CEO) & l I & [ ] & 11 & 11 & 1 \\
\hline & l l & [ ] & [ ] & [ ] & I \\
\hline & [ ] & I I & [ ] & [ ] & I \\
\hline & [ ] & [ ] & [ ] & [ ] & [ \\
\hline & [ ] & I ] & $1]$ & 1 1 & I \\
\hline & 11 & [ ] & l J & l I & I \\
\hline & [ ] & l I & [ ] & [ ] & 1 \\
\hline & [ ] & [ ] & l ] & [ ] & 11 \\
\hline & l I & [ ] & 11 & [ ] & I 1 \\
\hline
\end{tabular}

7. For what different period(s) of time (horizon) do actual budgets exist (not only strategies or objectives)? If you use several budgets with different horizons simultaneously, more than one answer may be appropriate.
I ] one month
[ one quarter
[ ] six months
[ ] one year
I ] over one year
[ ] other (please specify):

8. In this question, a business unit means a set of activities associated with a single product/service or a line of closely related products/services (Examples of business units: Automobiles; Photographic supplies; Shaving supplies; Electric power generating equip.; Soap, detergents and cleaning preparations). According to this definition, what is the degree of diversity of your company?

[ ] SINGLE business (more than $95 \%$ of the corporate revenues are attributable to one single business unit)

[ ] DOMINANT business ( $70 \%$ to $95 \%$ of the corporate revenues are attributable to one single business unit)

1 ] RELATED business (70\% or more of the corporate revenues are attributable to one group of related business units). A busi*'s unit is part of a group of related business units as long as it is tangibly related to at least at one other business unit in: th :-oup. Examples of group related business units: Photographic film, cameras, dyes, pigments and textile chemicals; Tape, adhesives, coated paper, film and projectors.

I ] UNRELATED business (less than $70 \%$ of the corporate revenues are attributable to any one group ol related business units). 


\section{Appendix A (continued)}

9. Are the line units organized as:
[ ] Cost centers
[ ] Profit centers
[ ] Mixed solution (with both profit and cost centers)
[ ] Other (please specify)

10. Which costing method are you using in your company?
[ ] Direct/variable costing
[ ] Absorption/full costing
[ ] Mixed or other method (please explain)

11. Are you using internal transfer pricing (announts clarged by one unit to another unit)?
[ ] Yes
[ ] No

If the answer is yes, which inethod(s) of pricing do you apply? Several answers are possible.

[ ] Cost-based method

[ ] "Cost plus defined profit"-based method

[ ] Market price

[ ] Negotiated between line managers, with no intervention of CEO

[ ] Price decided by CEO, considering the interest of the whole firm

[ ] Other (please specify)

12. Which types of budgets are you using in your company? Several answers are possible
I ] Fixed budgets (not revised during the whole period)
I I Fixed adjusted budgets (periodically revised for the remaining period)
I ] Flexible budgets
I ] Continuous or rolling budgets
[ ] Other (please specify)

13. What is the legal form of the line units?
[ ] Line units are separate legal entities (subsidiaries).
[ ] Line units are not separate legal entities.
I ] Some line units are separate legal entities, others are not.
[ ] Other (please specify)

Remarks or coinments (if necessary, indicate the number of the question that your remark/comment relates to):

May we list the name of your company as a participant in this survey (but without disclosing any specific response)?

$$
\text { [ ] Yes [ ] No }
$$

Are you interested in having your questionnaire returned with a summary of the results to this survey?

If yes, indicate your address below: $\quad$ [ ] Yes [ ] No 


\section{Appendix B}

\section{Questionnaire Construction, Sample Selection and Response Biases}

\section{B1. Construction of the Questionnaire}

The questionnaire is designed to provide evidence on the organization of the firm at the second level. We elicit whether the firm has profit or cost centers, and measure dependency of investments, firm size, the use of transfer pricing methods, the use of budgets and the firm's accounting-based compensation and promotion mechanisms. The answers to questions about size variables are compared to the same variables as listed on COMPUSTAT for verification.

The questionnaire is provided in Appendix A. To increase the response rate the questionnaire is kept to three pages and does not contain questions about financial data other than sales. Questions on financial data are expected to reduce the response rate for small firms.

A first draft of the questionnaire was reviewed with a psychology faculty member experienced in questionnaires to reduce the likelihood managers would misunderstand the questions. A revised draft was completed by two middle level managers in the Simon School's executive development program. After interviewing those managers, some small changes were made in the formulation of the questions and the questionnaire was mailed to the Vice- President Finance in 97 representative companies in our sample. The questionnaire was sent with a cover letter stating that on request the respondent would be provided with the aggregate results from the survey and the original copy of their completed questionnaire. Only trivial changes were made as a consequence of the 97 firm mailing (no questions were changed) and the questionnaire was sent to the remaining 1998 sample firms in early June 1988.

\section{B2. Sample Selection}

The sample of firms is obtained from the 1987 edition of Ward's Business Directory (Ward's) Volumes 1 and 2. That edition is based on annual reports and 10-K filings for 1985 data. A total of 2095 firms is drawn from Ward's. The sample is not random, but instead is selected to provide a range of firm sizes and industries. The 750 largest publicly-held industrial companies, the largest 525 privately-held industrial companies, the 110 largest commercial banks and the 110 largest insurance companies are drawn from Ward's Volume 1 which contains data on 43,134 firms. The 600 small industrial firms are drawn from Volume 2, which contains data on 39,651 firms with annual sales between $\$ 0.5$ million and $\$ 11$ million. The 600 firms are drawn from a list of firms with $\$ 10$ million in sales. They are the largest 600 firms (based on number of myees) on that list. The questionnaire was sent to all 2095 firms. Thirty-nine of the questionnaires were not delivered, primarily because the firms had gone out of business.

The initial sample is spread across a range of firm sizes and industries because the sample will also be used in other studies, some of which require data on small and privately-held firms and 


\section{Appendix B (continued)}

non-industrial firms. In this study, our measure of uncertainty requires that the firms be publicly traded and so we only use firms from the publicly-held industrial firm, commercial bank and insurance company categories.

In total 297 responses are received (14.4\%). CUSIP numbers could be identified for only 126 of those responses and five of the 126 responses did not have all questions answered. That left a sample of 121 firms for analysis.

\section{B3. Response}

Relative to other empirical studies in this area, the response rate $(14.4 \%)$ is low. Vancil (1978), Cress and Pettijohn (1985) and Daley, Jiambalvo, Sundem and Kondo (1985) report response rates of $35.3 \%, 27.4 \%$ and $39.7 \%$ respectively. One likely reason for our lower response rate is that while the previous studies survey large publicly-held companies, approximately $50 \%$ of our sample are small businesses or privately-held companies. Our response rate among the largest publicly-held companies (17.4\%) is higher than the overall response rate, but still less than the previous studies' response rates. A second likely reason for the lower response rate is the sensitive nature of some of the questions asked (for example, the ratio of cash bonus compensation to salary -see question 3 appendix A). The confidentiality problem is also suggested by the fact that 37 firms returned their questionnaires without identifying themselves. Three of these firms could be identified from the postmarks and other characteristics.

The prime response bias appears to be with respect to size. The median number of employees for all the firms in the respondent sample for which the number is available in Ward's ( 234 firms) is 5,000. The equivalent number for the nonrespondent sample ( 1636 firms) is 2,700. The median and Wilcoxon-Mann-Whitney tests (see Siegel and Castellan, 1988, sections 5.3 and 5.4) for differences in the median and distribution of employee numbers respectively between the respondent and nonrespondent samples are both significant at the $0.00 \mathrm{l}$ level. However, there is little response bias due to size among the COMPUSTAT firms surveyed. There are 623 COMPUSTAT firms included in the sample and $126(20 \%)$ of those firms responded. There is little difference in size between the responding and non-responding COMPUSTAT firms. Neither the median nor the Wilcoxon-Mann-Whitney tests allow rejection of the null hypothesis of no difference in size or number of employees at any reasonable probability level.

The distribution of firms across industries differs significantly between the respondent sample and the nonrespondent sample. The chi-square statistic for testing the null of no difference is significant at the $0.00 \mathrm{l}$ level. Utilities and financial and insurance companies are over rel sented in the respondent sample and the other industries are under represented. These differences at least partially reflect size differences. Utilities are even more over represented in the subsample investigated in this version of the paper and financial and insurance companies are under represented rather than over represented. 


\section{Appendix B (continued)}

The distribution of answers to the sales and employee number questions indicates that our 121 firm sample consists of large firms. However, the size of firms in the sample is insignificantly different from the size of COMPUSTAT firms that did not respond to the questionnaire. 


\section{Appendix C \\ Pearson Correlation Coefficients Among Variables ${ }^{a}$ Prob $($ Rho=0)}

\begin{tabular}{|c|c|c|c|c|c|c|c|c|c|}
\hline & DEC & KT & SNLOB & $\Delta \mathrm{KT}$ & UNC & DUNC & DEP & SIZE & REG \\
\hline \multirow[t]{2}{*}{ DEC } & 1.0000 & 0.5781 & 0.4780 & $0.0^{\circ}$ & 0.3505 & 0.3777 & -0.5010 & 536 & -0.5765 \\
\hline & 0.0000 & 0.0001 & 0.0001 & 0.3894 & 0.0001 & 0.0001 & 0.0001 & 0.0925 & 0.0001 \\
\hline \multirow[t]{2}{*}{$\mathrm{KT}$} & 0.5781 & 1.0000 & 0.5208 & -0.3203 & 0.2060 & 0.2211 & -0.5318 & 0.1211 & -0.5252 \\
\hline & 0.0001 & 0.0000 & 0.0001 & 0.0003 & 0.0234 & 0.0148 & 0.0001 & 0.1856 & 0.0001 \\
\hline \multirow[t]{2}{*}{ SNLOB } & 0.4780 & 0.5208 & 1.0000 & 0.3821 & 0.1136 & 0.1541 & -0.5395 & 0.2354 & -0.3545 \\
\hline & 0.0001 & 0.0001 & 0.0000 & 0.0001 & 0.2147 & 0.0915 & 0.0001 & 0.0093 & 0.0001 \\
\hline \multirow{2}{*}{$\Delta \mathrm{KT}$} & 0.0789 & -0.3203 & 0.3821 & 1.0000 & 0.0771 & 0.1318 & -0.0953 & 0.2146 & 0.0122 \\
\hline & 0.3894 & 0.0003 & 0.0001 & 0.0000 & 0.4006 & 0.1494 & 0.2981 & 0.0181 & 0.8942 \\
\hline \multirow[t]{2}{*}{ UNC } & 0.3505 & 0.2060 & 0.1136 & 0.0771 & 1.0000 & 0.9893 & -0.1724 & -0.0997 & -0.5416 \\
\hline & 0.0001 & 0.0234 & 0.2147 & 0.4006 & 0.0000 & 0.0001 & 0.0585 & 0.2761 & 0.0001 \\
\hline \multirow[t]{2}{*}{ DUNC } & 0.3777 & 0.2211 & 0.1541 & 0.1318 & 0.9893 & 1.0000 & -0.1979 & -0.0917 & -0.5377 \\
\hline & 0.0001 & 0.0148 & 0.0915 & 0.1494 & 0.0001 & 0.0000 & 0.0295 & 0.3169 & 0.0001 \\
\hline \multirow[t]{2}{*}{ DEP } & -0.5010 & -0.5318 & -0.5395 & -0.0953 & -0.1724 & -0.1979 & 1.0000 & -0.0186 & 0.3553 \\
\hline & 0.0001 & 0.0001 & 0.0001 & 0.2981 & 0.0585 & 0.0295 & 0.0000 & 0.8394 & 0.0001 \\
\hline \multirow[t]{2}{*}{ SIZE } & 0.1536 & 0.1211 & 0.2354 & 0.2146 & -0.0997 & -0.0917 & -0.0186 & 1.0000 & -0.0864 \\
\hline & 0.0925 & 0.1856 & 0.0093 & 0.0181 & 0.2761 & 0.3169 & 0.8394 & 0.0000 & 0.3456 \\
\hline \multirow[t]{2}{*}{ REG } & -0.5765 & -0.5252 & -0.3545 & 0.0122 & -0.5416 & -0.5377 & 0.3553 & -0.0864 & 1.0000 \\
\hline & 0.0001 & 0.0001 & 0.0001 & 0.8942 & 0.0001 & 0.0001 & 0.0001 & 0.3456 & 0.0000 \\
\hline
\end{tabular}

a $\mathrm{DEC} \quad=\quad$ Decentralization. Equals one if the second level units are all profit centers, zero if they are all cost centers and one-half if there are both profit and cost centers.

$\mathrm{KT}=$ Average knowledge type for the industries in which the firm operates.

NLOB $=$ Number of lines of business ( 4 digit SIC codes) the firm operates in.

SNLOB.$=$ Number of lines of business divided by sample maximum NLOB.

$\triangle \mathrm{KT}=$ Incremental knowledge type of multiple lines of business, SNLOB(1-KT)

$\mathrm{UNC}=$ Std. dev. of rate of return on equity for the 60 montls ended 12/87.

$\mathrm{DUNC}=\mathrm{UNC} / \mathrm{SQRT}\left\{1 / \mathrm{NLOB}+[(\mathrm{NLOB}-1) / \mathrm{NLOB}]^{*} \mathrm{CORR}\right\}$.

$\mathrm{CORR}=$ Average off diagonal correlation among the firm's lines of business at the two digit SIC level.

DEP = Dependency of business units. DEP is coded one through four for unrelated businesses, related businesses, dominant business and single business.

SIZE $=$ Sales for 1987 as per COMPUSTAT.

I $\mathrm{G}=$ Unity if the firm's primary industry is utility, transportation or communications. 


\section{References}

Arrow, K. J., 1974, The limits of organization (W. W. Norton \& Co., New York, NY)

Belsley, D. A., E. Kuh and R. E. Welsch, 1980, Regression diagnostics: Identifying influential data and sources of collinearity (Wiley, New York, NY).

Bishop, A., 1986, Solid-state relay handbook with applications, Howard W. Sams \& Co., Indianapolis, $\mathbb{I N}$.

Chandler, A. D. Jr., 1962, Strategy and structure: Chapters in the history of the industrial enterprise (The M.I.T. Press, Cambridge, MA).

Chandler, A. D. Jr., 1977, The visible hand: The managerial revolution in American business (Harvard University Press, Cambridge, MA).

Christie, A. A., 1982, The stochastic behavior of common stock variances: Value, leverage and interest rate effects, Journal of Financial Economics 10, 407-432.

Christie, A. A., 1989, Equity risk, the opportunity set, production costs and debt, unpublished paper (University of Rochester).

Cress, W. P. and J. B. Pettijohn, 1985, A survey of budget-related planning and control policies and procedures, Journal of Accounting Education 3, 61-78.

Daley, L., J. Jiambalvo, G. L. Sundem, and Y. Kondo, 1985, Attitudes toward financial control systems in the United States and Japan, Journal of International Business Studies, 91-110.

Demsetz, H., 1988, The theory of the firm revisited, Journal of Law, Economics, and Organization $4,141-161$.

Friedman, M., 1953, Essays in positive economics, University of Chicago Press, Chicago, IL.

Harris, M., Kriebel, C. H., and A. Raviv, 1982, Asymmetric information, incentives and intra-firm resource allocation, Management Science 28, 604-620.

Hayek, F. A., 1945, The use of knowledge in society, American Economic Review 35, 519-530.

Jensen, M.C. and W. H. Meckling (1992), Specific and general knowledge, and organizational structure, in L. Werin and H. Wijkander, eds., Main Currents in Contract Econonics, Blackwell, Oxford, U.K.

Kaplan, R. S., and A.A. Atkinson, 1989, Advanced management accounting, 2nd Ed., PrenticeHall, New Jersey.

Klein, B., Crawford, R. G., and A. Alchian, 1978, Vertical integration, appropriable rents, and the competitive contracting process, Journal of Law and Economics 21, 297-326.

March, J. G. and H. A. Simon, 1958, Organizations, John Wiley and Sons, New York.

Meckling, W. H. and M. C. Jensen, 1986, Divisional performance measurement, unpublished paper (University of Rochester).

Melumad, N., D. Mookherjee and S. Reichelstein, 1992, A theory of responsibility centers, Journal of Accounting and Economics, 15, 445-484.

Noreen, E., 1988, An empirical comparison of probit and OLS regression hypothesis tests, Journal of .:counting Research 26, 119-133. 
Rumelt, R. P., 1974, Strategy, structure, and economic performance (Harvard University Press, Cambridge, MA).

Siegel, S., and N. J. Castellan, 1988, Nonparametric statistics for the behavioral sciences, 2nd edition (McGraw- Hill Book Company, New York, NY).

Smith, C., and R. L. Watts, 1992, The investment opportunity set and corporate financing, dividend and compensation policies, Journal of Financial Economics, Dec.

Stone, M. and J. Rasp, 1991, Tradeoffs in the choice between Logit and OLS for accounting choice studies, The Accounting Review 66, 170-187.

Vancil, R., 1978, Decentralization: Managerial ambiguity by design (Dow Jones - Inwin, Homewood IL).

Vaysman, I., (1991), A model of cost-based transfer pricing, working paper, U. C. Berkeley.

White, H., 1980, A heteroskedasticity-consistent covariance matrix estimator and a direct test for heteroskedasticity, Econometrica 48, 817-838.

Williamson, O. E., 1975, Markets and hierarchies: Analysis and anti-trust implications (The Free Press, New York, NY). 